\title{
WestVirginiaUniversity
}

THE RESEARCH REPOSITORY @ WVU

Graduate Theses, Dissertations, and Problem Reports

2004

\section{Evaluation of the compacted aggregate resistance test}

\author{
Sean P. Rafferty \\ West Virginia University
}

Follow this and additional works at: https://researchrepository.wvu.edu/etd

\section{Recommended Citation}

Rafferty, Sean P., "Evaluation of the compacted aggregate resistance test" (2004). Graduate Theses, Dissertations, and Problem Reports. 1455.

https://researchrepository.wvu.edu/etd/1455

This Thesis is protected by copyright and/or related rights. It has been brought to you by the The Research Repository @ WVU with permission from the rights-holder(s). You are free to use this Thesis in any way that is permitted by the copyright and related rights legislation that applies to your use. For other uses you must obtain permission from the rights-holder(s) directly, unless additional rights are indicated by a Creative Commons license in the record and/ or on the work itself. This Thesis has been accepted for inclusion in WVU Graduate Theses, Dissertations, and Problem Reports collection by an authorized administrator of The Research Repository @ WVU. For more information, please contact researchrepository@mail.wvu.edu. 


\title{
Evaluation of the Compacted Aggregate Resistance Test
}

\author{
Sean P. Rafferty
}

Thesis submitted to the College of Engineering and Mineral Resources at West Virginia University in partial fulfillment of the requirements for the degree of

\author{
Masters of Science \\ In \\ Civil Engineering \\ Dr. John P. Zaniewski, Chair \\ Dr. Ronald W. Eck \\ Mr. David Jahn \\ Department of Civil and Environmental Engineering \\ Morgantown, West Virginia \\ 2004
}

Keywords: Compacted Aggregate Resistance, Fine Aggregate Angularity, Asphalt Pavement Analyzer, Rutting 


\section{ABSTRACT \\ Evaluation of the Compacted Aggregate Resistance Test}

\section{Sean P. Rafferty}

The Compacted Aggregate Resistance (CAR) test is a procedure used to analyze the quality of asphalt. It is a punch shear test that indirectly measures the shape and angularity of fine aggregates. The CAR test is in the developing process of replacing the current Superpave standard for fine aggregate angularity.

The primary objective of this paper is to determine if there is a direct correlation between the results from the CAR test and the quality of asphalt that corresponds to the results from an Asphalt Pavement Analyzer. Currently, there has been good quality Hot Mix Asphalt (HMA) that cannot pass the Superpave criteria for fine aggregate angularity. The goal of the CAR test is provide laboratory results to the quality of asphalt in the field. Field testing is not feasible for this research project; therefore an Asphalt Pavement Analyzer (APA) is used to determine the quality of the asphalt by the depth of the ruts it forms.

It was found that that the CAR test results correspond with the rut potential of the specimens. The CAR test results distinguish between blend gradations, whereas the Fine Aggregate Angularity test is determined by a predetermined gradation. The research concludes that with further refinement, the CAR test can be a useful tool for determining fine aggregate shape and angularity. 


\section{ACKNOWLEDGEMENTS}

I would like to thank my advisor Dr. John Zaniewski for his continuous support and encouragement. Without his guidance, this Masters of Science degree would not have been possible, your time and commitment has not gone unnoticed. Thanks!

I would like to thank Dr. Eck for his willingness to serve on my committee. His careful evaluation of my work, and willingness to make time for my defense was greatly appreciated.

I would also like to thank David Jahn from Martin Marietta Technologies for his help and support throughout my research. David has kept me current on the development of the subject matter of my research, and has been extremely helpful through the research process.

I would like to thank my parents for their love and support, and thank my sister and extended family for all of their encouragement and support.

I would like to thank Andy Kincell and the asphalt lab crew for their assistance and friendship. I would also like to thank all of my friends for always being there for me. 


\section{TABLE OF CONENTS}

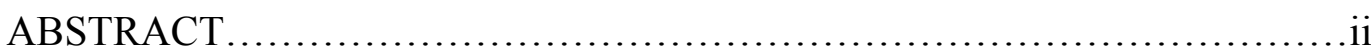

ACKNOWLEDGMENTS...................................................ii

TABLE OF CONTENTS .....................................................

CHAPTER 1 INTRODUCTION ................................................................ 1

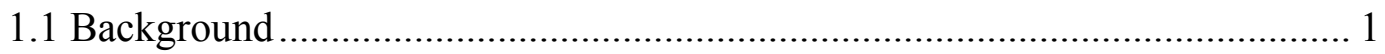

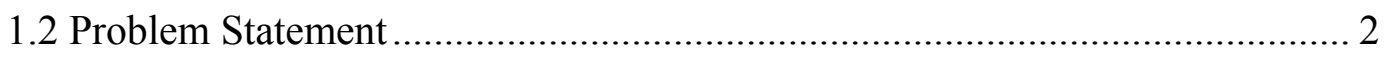

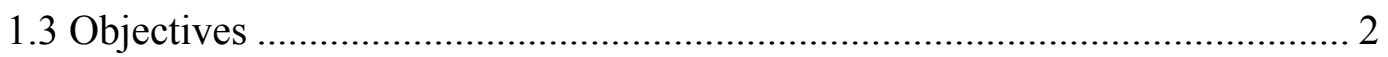

1.4 Scope of Work and Limitations .............................................................. 3

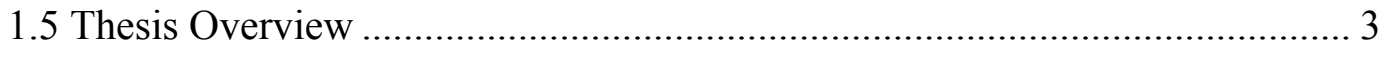

CHAPTER 2 LITERATURE REVIEW …................................................. 5

2.1 Introduction........................................................................................ 5

2.2 Fine Aggregate Shape and Texture ....................................................... 5

2.3 Test Methods Fine Aggregate Shape and Texture ..................................... 7

2.3.1 Visual Inspection Methods ................................................................ 7

2.3.2 Flow and Compaction Methods ......................................................... 8

2.3.2.1 Uncompacted Void Content.............................................................. 8

2.3.2.2 Flow Rate Method....................................................................... 11

2.3.2.3 New Zealand Test ................................................................... 11

2.3.2.4 Index of Aggregate Particle Shape and Texture ........................... 11

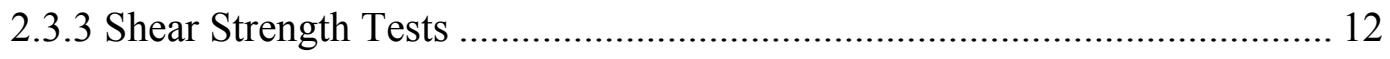

2.3.3.1 Direct Shear Test.................................................................. 13

2.3.3.2 Compacted Aggregate Resistance Test....................................... 13

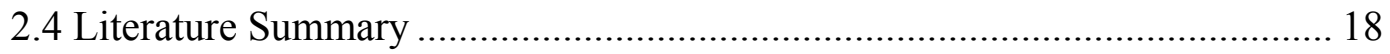


CHAPTER 3 RESEARCH METHODOLOGY ............................................... 20

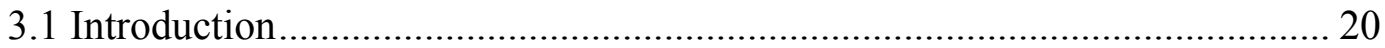

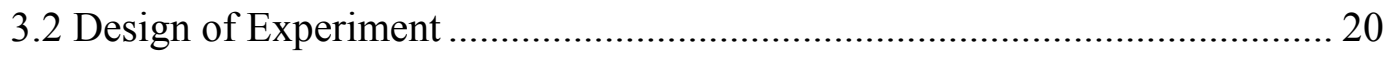

3.3 Aggregate Preparation ..................................................................... 22

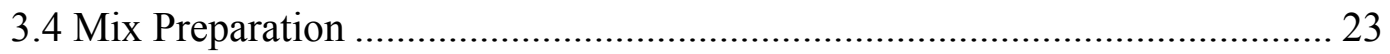

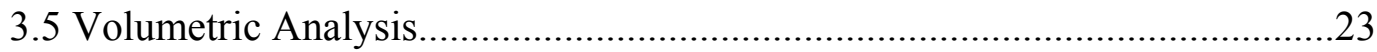

3.6 Asphalt Pavement Analyzer..................................................................... 25

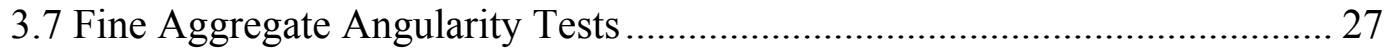

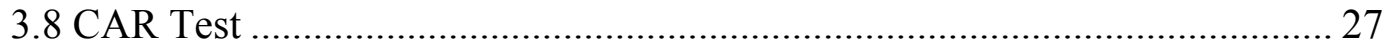

CHAPTER 4 RESULTS AND ANALYSIS ................................................. 29

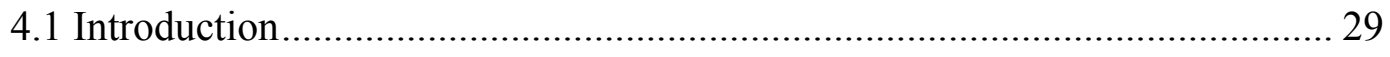

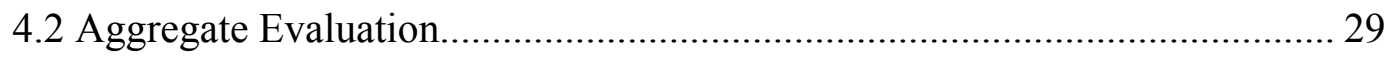

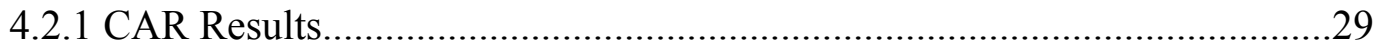

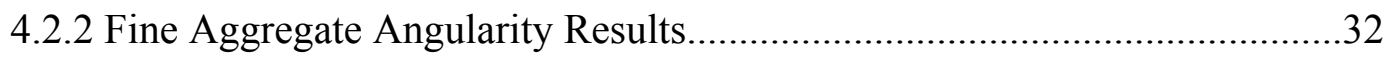

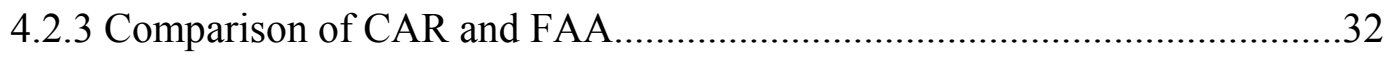

4.2.4 Evaluations and comparison with other studies..................................... 32

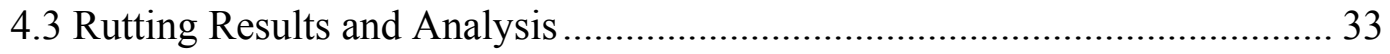

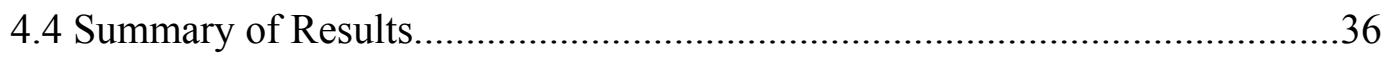

CHAPTER 5 CONCLUSIONS AND RECOMMENDATIONS ....................... 37

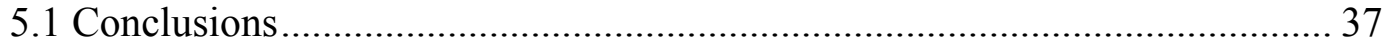

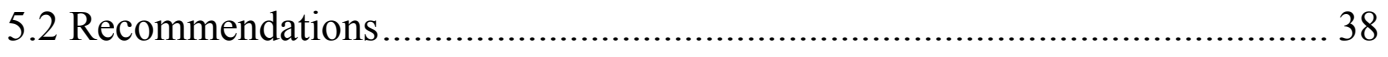

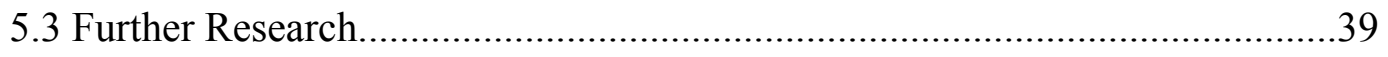

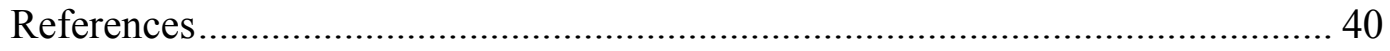

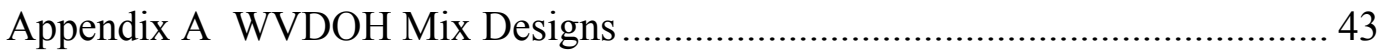


Appendix B CAR Testing Procedure...............................................................45

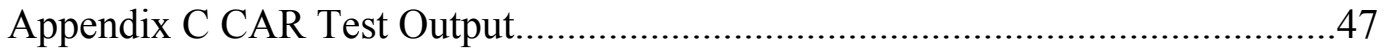

Appendix D Rut Depth Results.........................................................................52

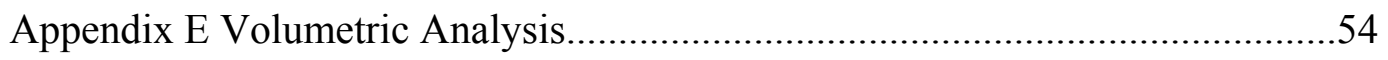

Curriculum Vitae.....................................................5 57 


\section{List of Tables}

Table 2.1 WVDOH Aggregate Requirements.................................................6

Table 3.2 Results of Fine Aggregate Angularity..............................................27

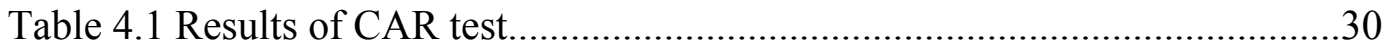

Table 4.2 Results of rutting potential tests with the APA....................................34 


\section{List of Figures}

Figure 2.1 Fine Aggregate Angularity apparatus.............................

Figure 2.2 CAR loading head for use with Marshall stabilometer.......................15

Figure 2.3 Typical CAR results.......................................16

Figure 2.4 Martin Marietta's moisture content testing results............................17

Figure 2.5 Martin Marietta's compaction results.............................................. 18

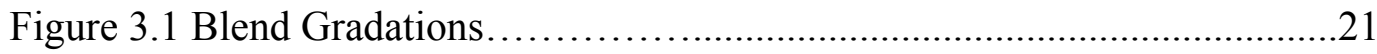

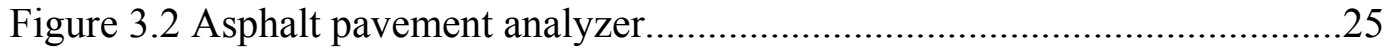

Figure 3.3 Measuring system for APA specimens........................................26

Figure 4.1 Effect of percent limestone on CAR force.......................................31

Figure 4.2 Fine Aggregate Angularity Results..............................................32

Figure 4.3 Effect of asphalt content, blend types and percent sand on rutting

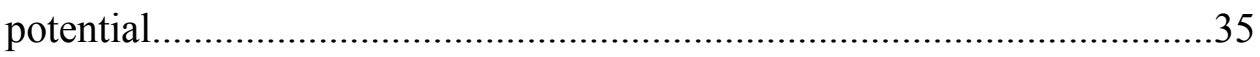

Figure 4.4 Relationship between CAR force and rutting potential for

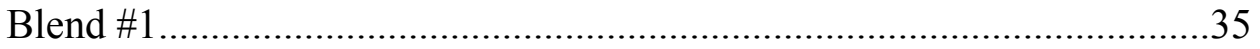

Figure 4.5 Relationship between CAR force and rutting potential for

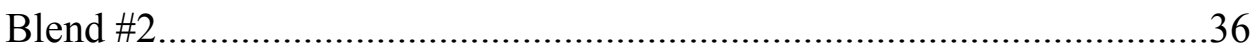

Figure C.1 Blend \#1 CAR results for 100\% limestone...................................47

Figure C.2 Blend \#1 CAR results for 75\% limestone/ 25\% natural sand..............47

Figure C.3 Blend \#1 CAR results for 50\% limestone/ 50\% natural sand.............48

Figure C.4 Blend \#1 CAR results for 25\% limestone/ 75\% natural sand.............48

Figure C.5 Blend \#1 CAR results for 100\% natural sand...................................49

Figure C.6 Blend \#2 CAR results for 100\% limestone....................................49

Figure C.7 Blend \#2 CAR results for 75\% limestone/ 25\% natural sand..............50 
Figure C.8 Blend \#2 CAR results for 50\% limestone/ 50\% natural sand..............50

Figure C.9 Blend \#2 CAR results for 25\% limestone/ 75\% natural sand..............51

Figure C.10 Blend \#2 CAR results for 100\% natural sand.....................................51 


\section{CHAPTER 1 INTRODUCTION}

\subsection{BACKGROUND}

The Strategic Highway Research Program (SHRP) was initiated in 1988 to study methods to reduce pavement problems caused by increases in traffic volumes and heavier vehicle loads which caused fatigue, rutting, and thermal cracking. The SHRP administered a $\$ 50$ million dollar project to improve Hot Mix Asphalt (HMA) technology. By 1993, the research produced the Superior Performing Asphalt Pavements (Superpave) $^{\mathrm{TM}}$ asphalt mix design method and performance grading for binders.

The research focused mainly on mix design and asphalt binder specifications, while giving less attention to aggregate properties. However, the research team then realized that investigating mineral aggregates would play a major role in HMA performance (Roque, 2002), so new aggregate test methods and specifications were developed for Superpave. However, since aggregate characteristics were not included in the original SHRP research plan, there was no time during the project to validate the aggregate specifications (Kandhal, 1998). In fact, the aggregate requirements are called consensus properties, which is indicative of the way the requirements were developed. One of these standards is the Fine Aggregate Angularity (FAA) test method and criteria. The FAA test was implemented to ensure that the fine aggregate has sufficient texture and angularity to provide a rut resistant mix. However, recent studies demonstrate that FAA requirements do not have the desired effect on the performance of asphalt concrete (Stakston, et al, 2002).

The SHRP researchers recommended FAA requirements of 45 and 40 percent voids for high and medium traffic volume roads respectively (AASHTO MP2, 2001). The reason for selecting this number is not well documented. Many state agencies and aggregate companies have trouble passing the FAA requirements, while still producing high quality asphalt (Roque, 2002). 


\subsection{PROBLEM STATEMENT}

Because the reliability of the FAA test and criteria are unclear, there have been several studies that evaluate the integrity of the test (Chowdury, et al, 2001, Stakston, et al, 2002, Roque, 2002, and White, 1998). The results are all very similar; they do not show a clear relationship between the FAA and the mixture performance. The implication of the lack of correlation between the FAA results and performance of a mix in the field is two fold:

- $\quad$ some fine aggregates could be approved and yet produce poor performing pavements, or

- $\quad$ some aggregate sources that would produce acceptable performance are being unnecessarily rejected.

Because FAA requirements have been questionable, the Compacted Aggregate Resistance (CAR) test was proposed as an alternative method for measuring fine aggregate properties with respect to their contribution to producing rut resistant mixes (Jahn, 2003). The CAR test is still under development. Ongoing research will determine if it can supplement or replace the FAA test. The CAR test is basically a "punch shear" that measures the shear resistance of compacted fine aggregates. Conceptually, the CAR test is similar to the California Bearing Ratio test. Although the initial evaluation of the CAR test appears promising, further research is needed to establish a performance relationship between CAR test results and the performance of asphalt concrete. Since the FAA test and criteria were implemented to ensure the rutting performance of mixes, then results from the CAR test should also be evaluated with respect to the rutting performance of mixes.

\subsection{OBJECTIVES}

The objective of this research is to determine if the CAR test is a suitable method for measuring and specifying the quality of fine aggregates with respect to their impact on the rutting potential of HMA. 


\subsection{SCOPE OF WORK AND LIMITATIONS}

In order to evaluate the CAR test as a method for controlling the quality of fine aggregate used in HMA, a series of mix designs were evaluated using a range of aggregate types, gradation blends, and asphalt contents. Two approved WVDOH mix designs were used to establish a baseline aggregate gradation blend and asphalt content. To ensure a range in the CAR test results, blends of crushed limestone and natural sand fine aggregates, passing the $2.36 \mathrm{~mm}$ sieve, were used in the different mixes. These blends of fine aggregate ranged from 100 percent crushed limestone to 100 percent natural sand in 25 percent increments. Thus, ten blends of fine aggregate were evaluated. A PG 70-22 asphalt cement supplied by Marathon-Ashland was used.

The rutting potential of the mixes were evaluated with the Asphalt Pavement Analyzer. This type of loaded wheel tester has been successfully used for several research projects for identifying the relative rutting potential of HMA (Skok, et al, 2002, Kandhal and Mallick, 1999, Kandhal and Cooley, 2002, Zaniewski and Kanneganti, 2003, Zaniewski and Nelson, 2003).

All mixes were prepared in the Asphalt Technology Laboratory at West Virginia University. A Pine Superpave Gyratory Compactor was used to prepare all samples. Samples prepared for evaluation of volumetric properties were compacted to an $\mathrm{N}_{\text {design }}$ of 100 gyrations. Samples prepared for rutting potential evaluation were compacted to an air void content of $7 \pm 0.5$ percent.

The work was limited to West Virginia $9.5 \mathrm{~mm}$ nominal maximum aggregate sizes, one source of PG 70-22 binder and two sources of aggregate. The approved mix designs were modified outside of their specification range for better CAR comparisons; therefore the tests were limited to laboratory testing.

\subsection{THESIS OVERVIEW}

This report is organized into five chapters and six appendices. After the first chapter of Introduction, Chapter 2 is a summary of literature review. Importance of fine aggregate quality is discussed as well as test methods for fine aggregate angularity are outlined with test procedures and specifications. The CAR test method is discussed in 
further detail including procedure and history. The research methodology and procedures for preparing, testing and analyzing samples is presented in Chapter 3. Chapter 4 presents the results of the experiment and the analysis of the results. Chapter 5 concludes the report with the conclusions and recommendations.

The mix designs used are presented in the Appendix A. Appendix B presents the CAR procedure followed during this research. The individual CAR output for each sample set is graphically presented in Appendix C. Appendix D and E presents respectively the rut depth results and volumetric data for each specimen tested. 


\section{CHAPTER 2 LITERATURE REVIEW}

\subsection{INTRODUCTION}

This review first analyzes the problems that the current test for measuring fine aggregate angularity has faced. A number of tests have been evaluated to supplement or replace the fine aggregate angularity test, but this study will focus on the CAR test, and compare the results to those of the APA.

\subsection{FINE AGGREGATE SHAPE AND TEXTURE}

Particle shape of aggregates is important for workability and performance of HMA. Cubicle-like particles, rather than flat, thin, and elongated particles are recommended for use in HMA (Roberts, et al, 1996). Angular particles, a property found in most crushed stone, provide a better interlocking property than rounded particles. This provides better performance and less rutting under repetitive traffic loads. However, this property also makes the workability during the compaction stage of construction more difficult. Rounded particles provide better workability during compaction, but tend to continue to compact under traffic loading due to the lack of interlocking particles.

The texture of aggregates is also important in the workability and performance of HMA (Roberts, et al, 1996). Rough surfaces are found in fine aggregates produced by crushing stone. Smooth-surfaced particles are often found in natural sand and gravel. A rough surface provides a greater bonding strength with asphalt cement and provides frictional resistance between particles. Due to the greater frictional resistance, fine aggregate with high texture require a greater amount of asphalt cement to increase the workability during construction, relative to the requirements for a smooth texture fine aggregate. A rougher texture is preferred in HMA where friction between particles is needed to provide stability.

It has been well documented that the characteristics of fine aggregates play a significant role in rutting resistance for HMA (Chowdury, et al, 2001, Purcell and Cross, 2001, Stakston, et al, 2002, and White, 1998). However, the SHRP researchers originally focused on the role of binder in the performance of HMA. The need to include aggregate 
specifications was not addressed until late in the SHRP program. As a result, an expert committee formulated Superpave aggregate specifications based on their experience and using existing tests. These are identified as the consensus properties which are required for all Superpave mixes, regardless of geographic location (Harman, et al, 2002). State agencies are allowed to supplement the consensus properties with local requirements known as source properties. Superpave requires the following consensus properties:

- Coarse Aggregate Angularity (ASTM D5821) - materials retained on $4.75 \mathrm{~mm}$ sieve.

- Fine Aggregate Angularity (AASHTO T304) - materials passing the $2.36 \mathrm{~mm}$ sieve.

- Flat \& Elongated particles (ASTM D4791) - materials retained on $9.5 \mathrm{~mm}$ sieve.

- Sand Equivalent (AASHTO T176) -materials passing the $4.75 \mathrm{~mm}$ sieve.

Aggregate property requirements set forth by WVDOH are shown in Table 2.1 (WVDOH, 2000).

Table 2.1 WVDOH Aggregate Requirements

\begin{tabular}{|c|c|c|c|c|c|c|}
\hline \multirow{2}{*}{$\begin{array}{l}\text { Design } \\
\text { ESALs } \\
\text { (Million) }\end{array}$} & \multicolumn{2}{|c|}{$\begin{array}{l}\text { Coarse Aggregate } \\
\text { angularity }(\% \mathrm{~min}) *\end{array}$} & \multicolumn{2}{|c|}{$\begin{array}{c}\text { Fine aggregate } \\
\text { angularity }(\% \mathrm{~min})\end{array}$} & \multirow{2}{*}{$\begin{array}{l}\text { Sand } \\
\text { equivalent } \\
\text { Percent } \\
\text { minimum }\end{array}$} & \multirow{2}{*}{$\begin{array}{l}\text { Flat \& } \\
\text { elongated } \\
\text { Percent } \\
\text { minimum }\end{array}$} \\
\hline & $\begin{array}{l}100 \mathrm{~mm} \\
\text { from } \\
\text { surface }\end{array}$ & $\begin{array}{c}>100 \\
\text { mm } \\
\text { from } \\
\text { surface }\end{array}$ & $\begin{array}{c}100 \\
\text { mm } \\
\text { from } \\
\text { surface }\end{array}$ & $\begin{array}{l}>100 \mathrm{~mm} \\
\text { from } \\
\text { surface }\end{array}$ & & \\
\hline$<0.3$ & $55 /-$ & - & - & - & 40 & - \\
\hline 0.3 to $<3$ & $75 /-$ & $50 /-$ & 40 & 40 & 40 & 10 \\
\hline$<10$ & $85 / 80$ & $60 /-$ & 45 & 40 & 40 & 10 \\
\hline 10 to $<20$ & $90 / 95$ & $80 / 75$ & 45 & 40 & 45 & 10 \\
\hline 20 to $<30$ & $95 / 90$ & $80 / 75$ & 45 & 40 & 45 & 10 \\
\hline 30 & $100 / 100$ & $100 / 100$ & 45 & 45 & 50 & 10 \\
\hline
\end{tabular}

*The first number indicates the minimum percent of course aggregates with at least one fractured face. The second number is the required minimum percent of coarse aggregate with more than one fractured face. 
The design criterion for Superpave uses an AASHTO test method T 304, Uncompacted Void Content of Fine Aggregates. This test provides an indirect measure of angularity (Roque, 2002). The FAA requirement was implemented based on the assumption that more angular fine aggregates will interlock and create a stronger shear resistance than rounder particles. This concept is correct, however, there are other factors that influence rutting resistance, including particle texture, toughness, gradation, VMA and compaction (Roque, 2002). Some state agencies have reported that mixes that are performing well in the field included fine aggregates that do not meet the current FAA requirements. Some agency and industry representatives are suggesting a more direct method of testing by adding a strength or torture test to the Superpave system (Roque, 2002). One proposal for evaluation fine aggregates is the CAR test, a punch shear test that measures the stability of compacted fine aggregates (Chowdury, et al, 2001).

\subsection{TEST METHODS FOR FINE AGGREGATE SHAPE AND TEXTURE}

Chowdury, et al (2001) prepared an excellent report of the various fine aggregate test methods that provided the basis for the following review. The angularity of fine aggregates may be evaluated with either direct or indirect methods. Direct methods evaluate angularity by inspection of the aggregate. Indirect methods test the behavior of the aggregates, and relate the quality of the behavior to the angularity. Due to the size of fine aggregates, it is not feasible to manually evaluate their shape and texture as is done for coarse aggregates. With the advent of digital images and computer analysis, several methods have recently been developed to measure shape and texture directly. However, the state of the art has not developed to the point where these methods can be recommended for implementation. For completeness, a brief review of these methods is presented, but they were not considered for use during this research due to their experimental nature. Indirect measures of shape and texture are based either on measuring the shear resistance of the aggregate or on the ability of the aggregate to flow and pack into a cylinder.

\subsubsection{Visual Inspection Methods}

Visual inspection methods have recently been developed using machine vision to capture an image of the aggregate and complex algorithms to process the image into 
information about size, shape and texture. Research is ongoing in France, and at the Universities of Texas, Washington, and Missouri to develop technologies for capturing digital images and processing them into useful information about aggregate size, shape and texture. The level of sophistication used for this approach of aggregate evaluation is not feasible for implementation by highway agencies at this time.

\subsubsection{Flow and Compaction Methods}

The shape and surface texture of fine aggregate affect the packing of the aggregates as they flow into a container, pass through an orifice, or compacted into a container. Based on this observation, several test methods have been developed to quickly and economically evaluate the surface texture and shape of fine aggregates.

\subsubsection{Uncompacted Void Content}

ASTM C-1252 (equivalent to AASTHO T-304) "Uncompacted Void Content of Fine Aggregates" provides an indirect measure of fine aggregate texture and angularity. This is the method referred to as either the National Aggregate Association (NAA) Flow Test, or the Fine Aggregate Angularity (FAA) test. In this test, the FAA is described as the percent of air voids present in uncompacted aggregates. The test is limited to aggregates finer than $2.36 \mathrm{~mm}$. The apparatus used in this test is shown in Figure 2.1. A sample of dry fine aggregate is placed into the apparatus, and falls through the cone into a calibrated cylinder. The orifice in the cone is $12.5 \mathrm{~mm}(0.5 \mathrm{inch})$. The height from the orifice of the cone and the rim of the cylinder is $114 \mathrm{~mm}(4.5 \mathrm{inch})$. The theory behind this test is that the higher the uncompacted void content, the more freshly fractured faces and highly textured particle faces. 


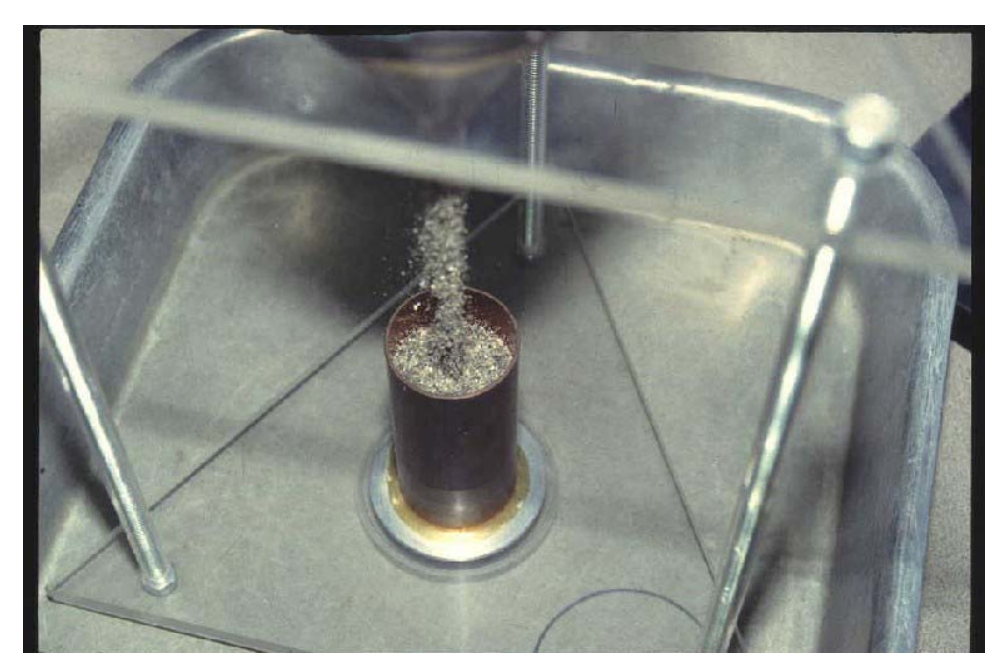

Figure 2.1 Fine Aggregate Angularity Apparatus

The uncompacted void content is determined as:

$$
U=\frac{\left(V-F / G_{s b}\right)}{V} 100
$$

Where:

$\mathrm{U}=$ uncompacted voids in the fine aggregate, $\%$

$\mathrm{V}=$ volume of calibrated cylinder, $\mathrm{ml}$

$\mathrm{F}=$ mass of fine aggregate in the cylinder, gm, and

$\mathrm{G}_{\mathrm{sb}}=$ bulk dry specific gravity of fine aggregate.

The test procedure provides three methods: Method A, B, and C. Method A uses a specific gradation, Method B uses three separate aggregate size fractions, and Method C uses "as received" materials passing the $4.75 \mathrm{~mm}$ (No. 4) sieve. The gradation for Method A is:

Individual Size Fraction

$2.36 \mathrm{~mm}$ (No. 8) to $1.18 \mathrm{~mm}$ (No.16)

$1.18 \mathrm{~mm}$ (No.16) to $0.60 \mathrm{~mm}$ (No.30)

$0.60 \mathrm{~mm}$ (No. 30) to $0.30 \mathrm{~mm}$ (No. 50)

$0.30 \mathrm{~mm}$ (No. 50 ) to $0.075 \mathrm{~mm}$ (No. 100)
Mass, gm

44

57

72

17

Total: $190 \mathrm{gm}$ 
The Superpave methodology specifies the use of Method A. The criteria for an acceptable fine aggregate are a function of the design traffic for the pavement section and the depth of the material in the pavement structure as presented in Table 2.1.

Chowdury, et al (2001) performed an extensive study of different methods for evaluating shape and texture, and a limited study of their relationship to rutting potential as measured with the Asphalt Pavement Analyzer. Their conclusion relating FAA and rutting potential was:

These limited findings indicate that FAA does not correlate well with rut resistance of HMA mixtures. Further, certain fine aggregates with a FAA value lower than 45 (limestone), or even lower than 43 (blend 2), but with relatively high particle surface texture, can produce mixtures with relatively good rut resistance.

Martin Marietta, a major aggregate supplier throughout the United States, found significant concerns with the FAA test as implemented in Superpave. The research team found several research reports cited from a variety of sources, including:

- NCAT,

- TRB,

- ICAR,

- NCHRP,

- SEAUPG,

- $\quad$ and Pooled Fund176.

These demonstrated poor correlation between FAA results and the performance of HMA (Jahn, 2003). Conclusions in 21 research reports that show FAA is not a suitable test for characterizing fine aggregate; it has a poor correlation with pavement deformation, and several DOT's do not apply FAA requirements (Marek, 2002). For example, the WVDOH has recently proposed lowering the FAA requirement from 45 to 43 for asphalt concrete mixes that use 100 percent crushed products (Barker, 2003). 


\subsubsection{Flow Rate Method}

This method is similar to the FAA test in that it uses a standard funnel to indirectly evaluate the shape and texture of fine aggregates. In this procedure, a specific weight and size fraction of aggregates are poured through a funnel; the time it takes to flow through the orifice is measured. The flow rate is determined by dividing the volume

of the sample, in $\mathrm{cm}^{3}$, by the flow time in seconds. The volume of the sand is determined by the weight divided by the bulk dry specific gravity. The flow rate of a standard set of round balls is measured. A shape-texture index (STI) is computed as the ratio of the flow rate of the standard balls divided by the flow rate of the sand. Because the flow rate for the standard set of round balls is constant, the STI changes proportionally with the flow rate of the aggregates

The flow rate method is relatively simple and inexpensive, but has not been widely accepted. There have been a number of tests done using different weights of aggregate and size fractions, but a national standard has not been developed.

\subsubsection{New Zealand Test}

The New Zealand test is similar to the previously mentioned methods (Chowdury, et al, 2001). A 1000 gram sample of fine aggregate passing the $2.36 \mathrm{~mm}$ sieve is placed through a standard funnel. The uncompacted void content, and the time it takes for the sample to pass are recorded. These measurements are used to indirectly evaluate particle shape and texture.

\subsubsection{Index of Aggregate Particle Shape and Texture}

This is another indirect method of determining fine aggregate shape and texture (Roberts, et al, 1996). This procedure consists of a combination of four different sieve sizes:

$2.36 \mathrm{~mm}$ (No. 8) to $1.18 \mathrm{~mm}$ (No. 16)

$1.18 \mathrm{~mm}$ (No. 16) to $0.60 \mathrm{~mm}$ (No. 30)

$0.60 \mathrm{~mm}$ (No. 30 ) to $0.30 \mathrm{~mm}$ (No. 50 ) 
$0.30 \mathrm{~mm}$ (No. 50) to $0.075 \mathrm{~mm}$ (No. 100)

A sample of each size is combined and compacted into three separate layers. The layers are compacted in a mold with a specific height and diameter depending on the aggregate size. Each layer receives 10 drops from a tamping rod 2 inches above the specimen. The weight of the tamping rod is determined by the size fraction of the aggregate. The percentage of voids, $\mathrm{V}_{10}$, is calculated as the difference between the volume of the mold and the absolute volume of the sand. The absolute volume of the sand is calculated by dividing the mass of the sample by the bulk dry specific gravity. The procedure is repeated using 50 blows from the tamping rod giving the percentage of voids $\mathrm{V}_{50}$. A shape index, $\mathrm{I}_{\mathrm{a}}$, is calculated as:

$\mathrm{I}_{\mathrm{a}}=1.25 \mathrm{~V}_{10}-0.25 \mathrm{~V}_{50}-32.0$

where,

$\mathrm{I}_{\mathrm{a}}=$ particle index value;

$\mathrm{V}_{10}=$ percent voids in the aggregate compacted with 10 blows per layer; and

$\mathrm{V}_{50}=$ percent voids in the aggregate compacted with 50 blows per layer.

The shape index, $I_{a}$, for the original fine aggregate is determined by calculating the weighted average of $I_{a}$ for all size fractions in the original gradation. A rounded aggregate with a smooth texture may have an index of 6 or 7, where a more angular aggregate with a rough surface may have an index of 15 to 20 or more. The test is time consuming, and, therefore, not commonly used.

\subsubsection{Shear Strength Tests}

The existing Superpave specification for fine aggregate angularity is an attempt to limit the aggregate's contribution to rutting potential of HMA. FAA is a surrogate for shape and texture, which in turn is a surrogate for a measure of the shear resistance capacity of the aggregate. Shear test methods for evaluating the angle of internal friction of fine aggregates are available and should be considered in the review and evaluation of the Superpave mix design materials specification. 


\subsubsection{Direct Shear Test}

The direct shear test can be applied to a cohesionless soil, e.g. sand, to measure the angle of internal friction. This provides an indirect measure of shape and texture, as particles with high angularity and texture have a higher angle of internal friction than rounded and smooth particles. To measure shear resistance, an air dried sample is placed into a direct shear apparatus for soil (ASTM D 3080). The box is split horizontally, with either the top half or bottom half held stationary and the other half allowed to move when a shearing force is applied. A normal stress is used to keep the sand consolidated. The shear strength is measured at three different normal stresses, and the angle of internal friction is the slope of the shear strength versus normal stress diagram.

Chowdury, et al (2001) found a correlation between rutting potential and the direct shear test; however, the correlation coefficient, $\mathrm{R}^{2}$, for their regression equation that relates the angle of internal friction and rut resistance was 0.69. The direct shear test provides a measure of a fundamental engineering property. However, the biaxial load requirements of the test require equipment that is not readily available to highway agencies.

\subsubsection{Compacted Aggregate Resistance Test}

The CAR test is a punch shear method, which measures the resistance of compacted fine aggregates. The CAR test uses standard Marshall equipment along with a simple loading head, Figure 2.2, for evaluating the shear resistance of fine aggregates. The CAR test shows potential for evaluating fine aggregates with respect to their contribution to the rutting potential of HMA. The test procedure is summarized as:

- The gradation of the fine aggregates used in the mix design is used for the test.

- The aggregates are dried then brought to the required moisture content.

- The aggregates are placed in a 4" Marshall mold and rodded to provide initial compaction.

- The sample is compacted using a standard Marshall hammer and drop height; 50 blows are applied to one face of the sample. 
- The sample is placed in a Marshall stabilometer configured with a punch loading head as shown in Figure 2.2.

- The load is applied at a rate of 2 inches per minute and the force and deformation are recorded.

- A typical CAR output is shown in Figure 2.3. The CAR result is the peak force measured during the test, or the force (lbs) at a deformation of 0.25 inches if the strength of the material exceeds the maximum load capacity of the machine. Jahn (2004b) justified the use of measuring CAR force at 0.25 inches based on the following arguments:

- Some cubical limestone materials have a peak punch shear resistance in excess of 25,000 pounds. This is beyond the capabilities of the Marshall stabilometer.

- Typically technicians using the Marshall stabilometer are familiar with reading results on recording charts scaled for 5000 pounds maximum force.

- Materials in which CAR force are in excess of 5000 pounds have high shear resistance, and are therefore acceptable for producing rut resistant mixes.

- The CAR test, like the FAA test, provides an evaluation of aggregate properties prior to the mix design process. A simple test, using readily available equipment was an objective of the development of the CAR test. Requiring users to purchase higher capacity equipment is inconsistent with the objective of the test method.

In 1995, Martin Marietta's research team became aware that cubicle shaped, 100 $\%$ limestone fine aggregate could be rejected by the FAA test, yet produce high quality HMA (Jahn, 2004a). The Martin Marietta research team, led by David Jahn, found a possible replacement for the FAA test from Indiana DOT's previously used Florida Bearing Ratio Test. Equipment for the Florida Bearing Ratio test was difficult to obtain, but the test was based on a punch shear mechanism that could be achieved by modifying Marshall equipment. 


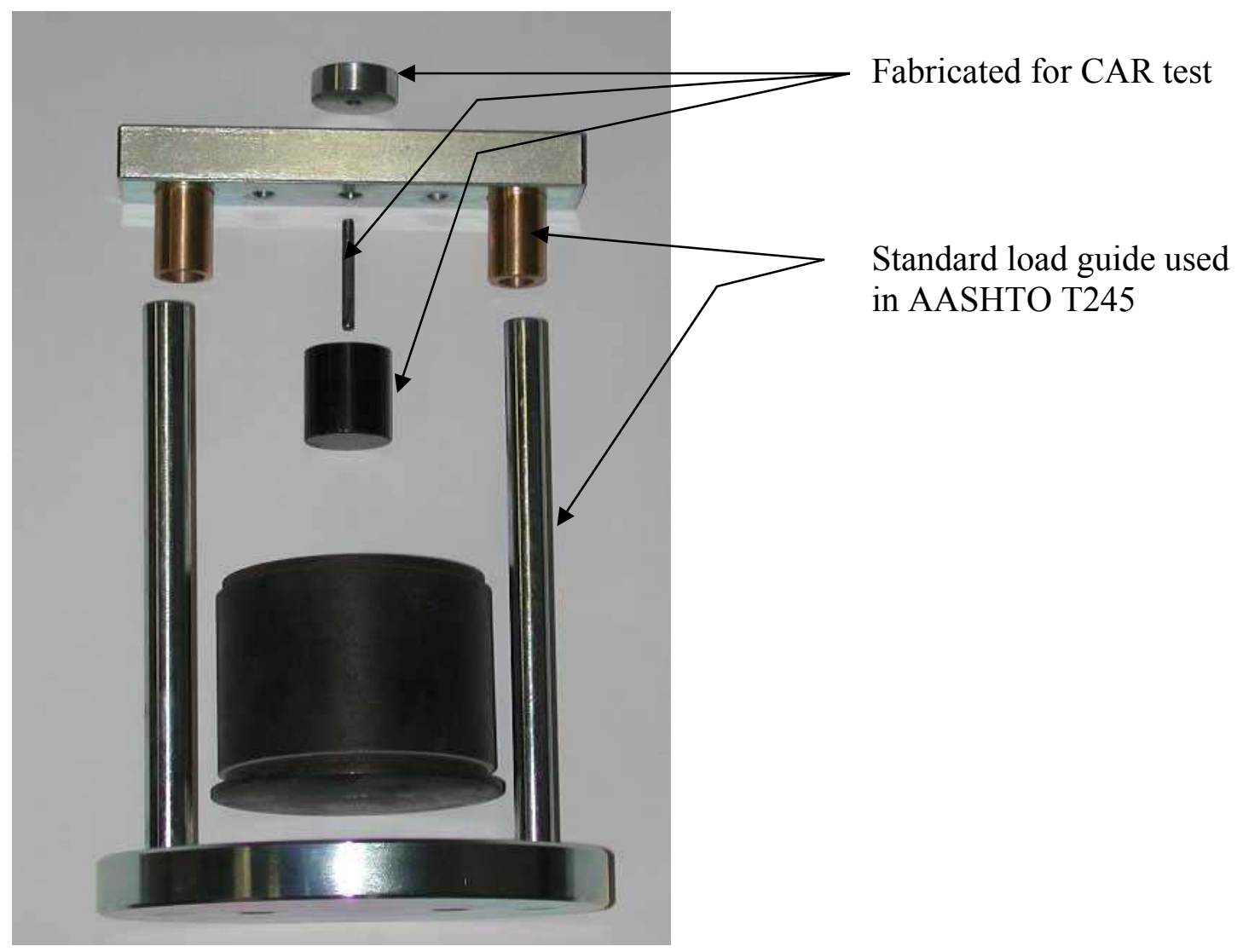

Figure 2.2 CAR loading head for use with Marshall stabilometer

The Florida Bearing Ratio Test used a moisture content of 1.75 percent for testing, this is the number used in the original CAR testing protocol. However, there was a concern that the results could be sensitive to moisture content. An experiment was performed using moisture contents of 1-5 percent, with two aggregate sources, producing the results displayed in Figure 2.3 (Jahn, 2003). The CAR results are affected by low moisture contents; however, the results appear to be consistent for moisture contents greater than three percent. Based on this evaluation, Jahn recommended using a moisture content of 3.5 percent as a standard for all aggregates. 


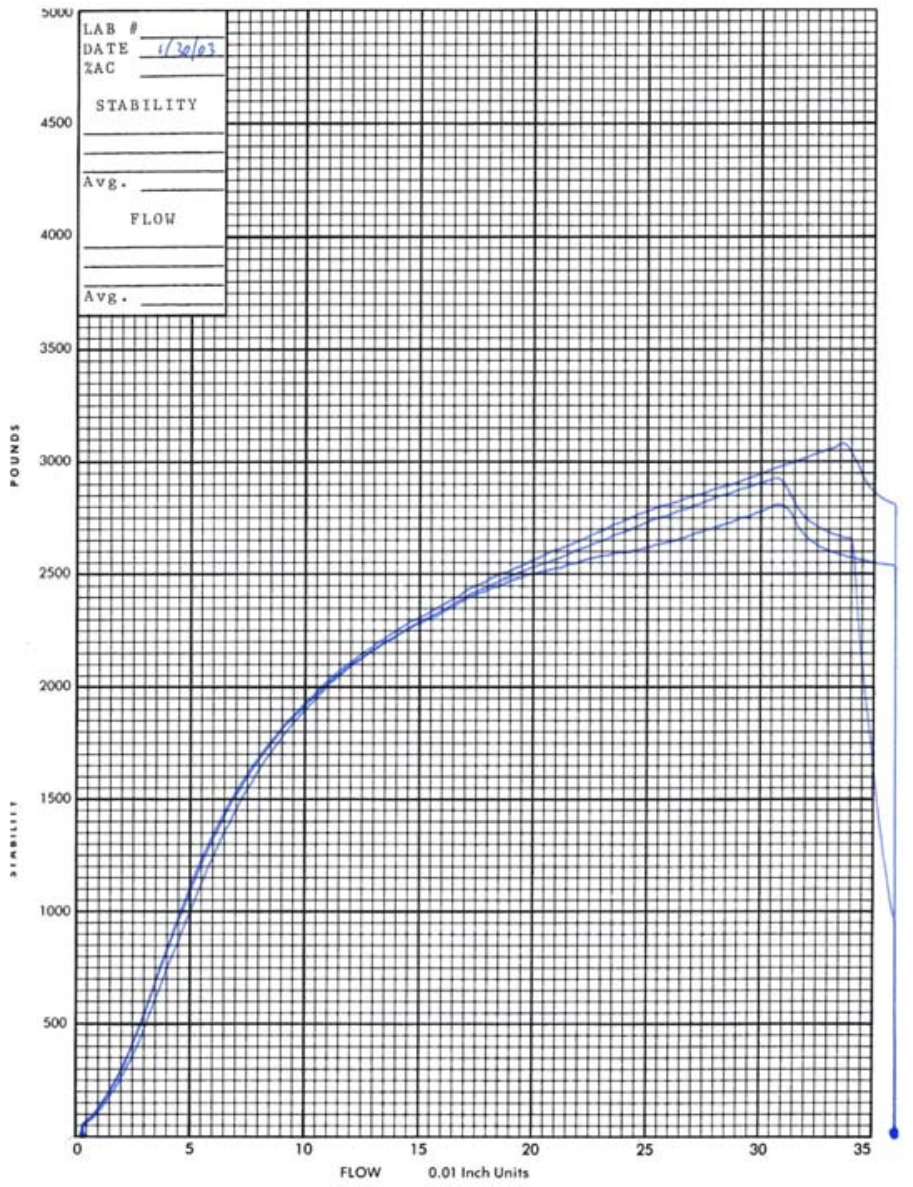

Figure 2.3 Typical CAR results

The research team decided on materials passing the $2.36 \mathrm{~mm}$ sieve for the original protocol, as does the Florida Bearing Ratio Test and the Fine Aggregate Angularity test. The Fine Aggregate Angularity Test, method A, uses a constant blend of aggregates passing the $2.36 \mathrm{~mm}$ sieve and also requires specific gravity to determine the results. The CAR test eliminates the need for specific gravity computation and uses the "as received" gradations. The research team has currently been testing materials passing the $4.75 \mathrm{~mm}$ sieve, as recommended by the NCAT (Jahn, 2004b). 


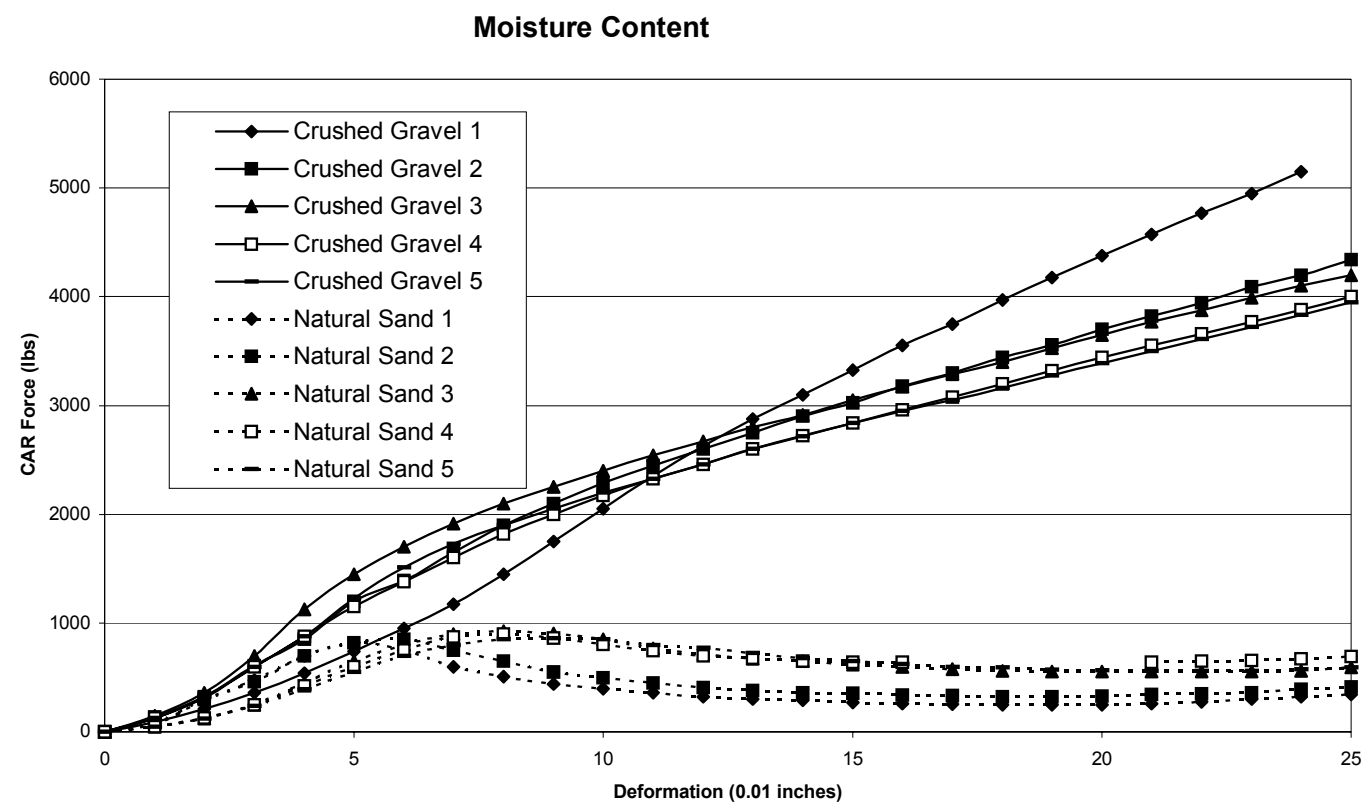

Figure 2.3 Martin Marietta's moisture content testing results

The research team also experimented with the compaction effort of the Marshall hammer. The original protocol also requires 50 blows to one face of the sample. Experiments demonstrated that 50 blows provide adequate compaction to achieve consistent results. Figure 2.4 shows the results of an experiment where different levels of compactive effort were used to prepare the samples. While the CAR results are correlated with the compactive effort, there is no difference in the ability of the test to identify the relative performance of the aggregates. Hence, 50 blows on one side of the sample was selected as the compactive effort for the CAR test.

Studies by Jahn indicate the CAR test has a good ability to distinguish the shear capacity of different aggregates with good repeatability. However, the ability of the CAR results to accurately indicate the contribution of fine aggregates to the rutting potential of a mix has not been sufficiently evaluated to allow the development of a criterion that can be used for specifying materials for mix design. 
Compactive Effort

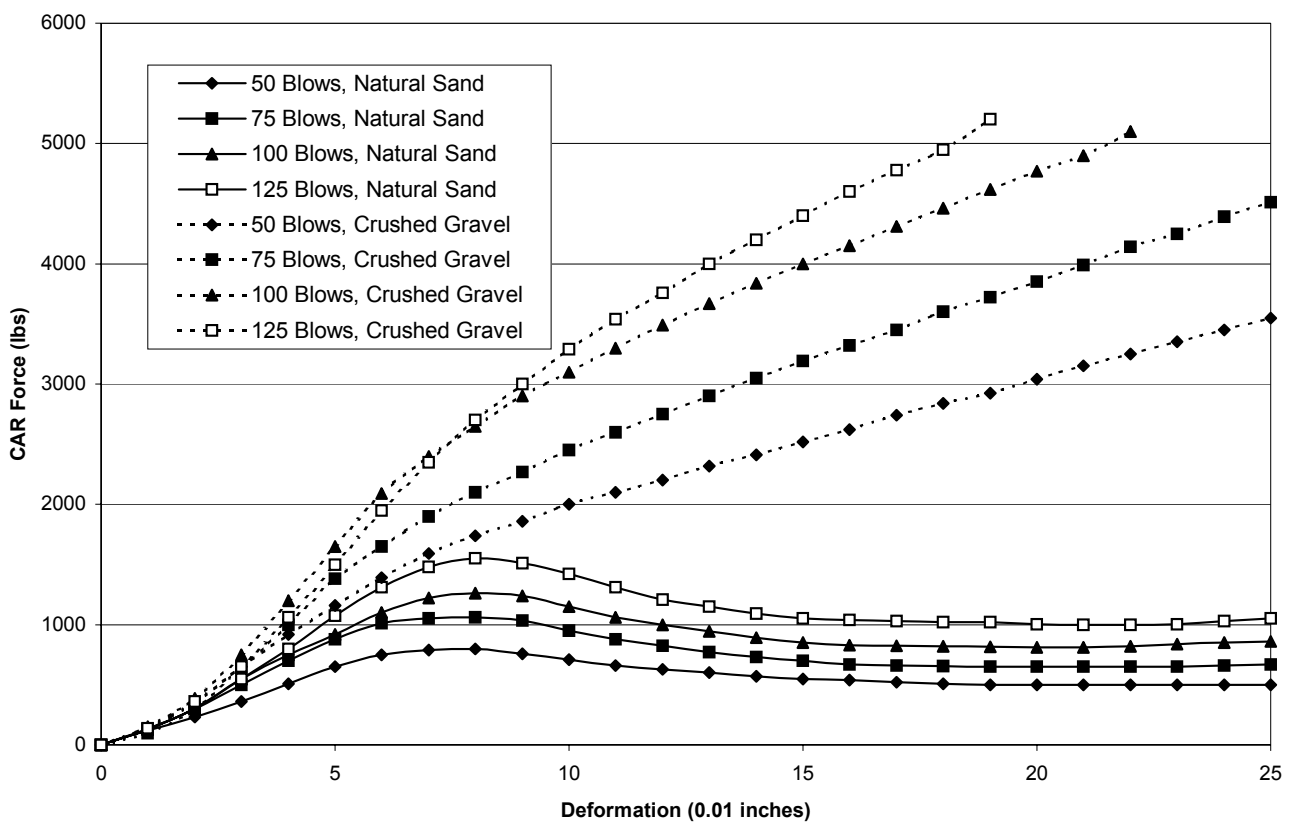

Figure 2.4 Martin Marietta's compaction results

There is ongoing research to evaluate the CAR test (Jahn, 2004a). Research at NCAT has suggested inclusion of all material passing the $4.75 \mathrm{~mm}$ sieve. The test method is also being evaluated in a project at Michigan Tech University.

\subsection{LITERATURE SUMMARY}

There are a variety of methods for evaluating fine aggregate characteristics. For the purposes of developing a specification for the use of a fine aggregate material in asphalt concrete, the procedure should provide direct evidence of the contribution that the fine aggregate will make to the rutting resistance of a mix. The SHRP researchers selected the Fine Aggregate Angularity method. While this is a simple and easy to perform method, it has been criticized in the literature for not correlating well with the rutting potential of asphalt mixes and for rejecting aggregates with a proven record of acceptable performance. This has lead researchers to search for a viable candidate to replace the current Superpave FAA requirement. 
The direct shear test is a fundamentally sound test that provides a direct measure of an aggregate's angle of internal friction. However, this test method requires equipment that is not readily available in materials laboratories of state highway agencies.

The Compacted Aggregate Resistance test has the potential to fulfill the need for providing a reliable evaluation of the ability of a fine aggregate to contribute to the rutting resistance of an asphalt concrete mix. The CAR test offers the advantage of using readily available equipment. The only additional equipment cost is for the loading head used for the test. 


\section{CHAPTER 3 RESEARCH METHODOLOGY}

\subsection{INTRODUCTION}

Research by Jahn has demonstrated the potential of the CAR test as a replacement for the FAA method as a specification tool for evaluating fine aggregates used in asphalt concrete. However, the CAR test is not ready for implementation at this time. Issues that need to be resolved include:

- the ability of independent laboratories to reliably perform the test,

- refinements to the testing methodology, and

- the development of specification criteria for the acceptance or rejection of an aggregate source.

The following research methodology was designed to address these issues.

\subsection{DESIGN OF EXPERIMENT}

All materials used during the research are commonly used for asphalt concrete mixes in West Virginia. Initial proportioning of the materials was based on WVDOH approved mix designs as given in Appendix A. Two mix designs were evaluated during the research, a Superpave $9.5 \mathrm{mix}$, and a Marshall Wearing I skid mix. Both mix types have a $9.5 \mathrm{~mm}$ nominal maximum size aggregate. The Marshall mix had an optimum asphalt content of 6.3 percent and used four aggregate stockpiles, \#8 limestone, \#8 dolomite, crushed limestone fine aggregate and natural sand, with blend proportions of $22,22,28$, and 28 percent, respectively. The Superpave mix design had an optimum asphalt content of 5.7 percent and also used four stockpiles, however, they were all crushed limestone material. The aggregates used in the Superpave mix design were \#8, \#9 and two fine aggregate stockpiles. For simplicity, the tests using the Superpave mix design combinations will be referred to as Blend \#1, and the tests done with the Marshall mix design combination will be referred to as Blend \#2. Figure 3.1 shows the gradation of the two mixes. The lines on the right side of the figure are the overall gradations used in the mix design. The lines on the left side of the figure are the gradations for the 
material passing the $2.36 \mathrm{~mm}$ sieve; these are the gradations evaluated during the CAR test. Figure 3.1 shows that Blend \#1 is slightly finer than Blend \#2. When considering the gradation of the material passing the $4.75 \mathrm{~mm}$ sieve, the two blends are identical for material retained on the $0.600 \mathrm{~mm}$ sieve. Blend \#1 is finer than Blend \#2 for material finer than $0.600 \mathrm{~mm}$, however the difference is relatively small.

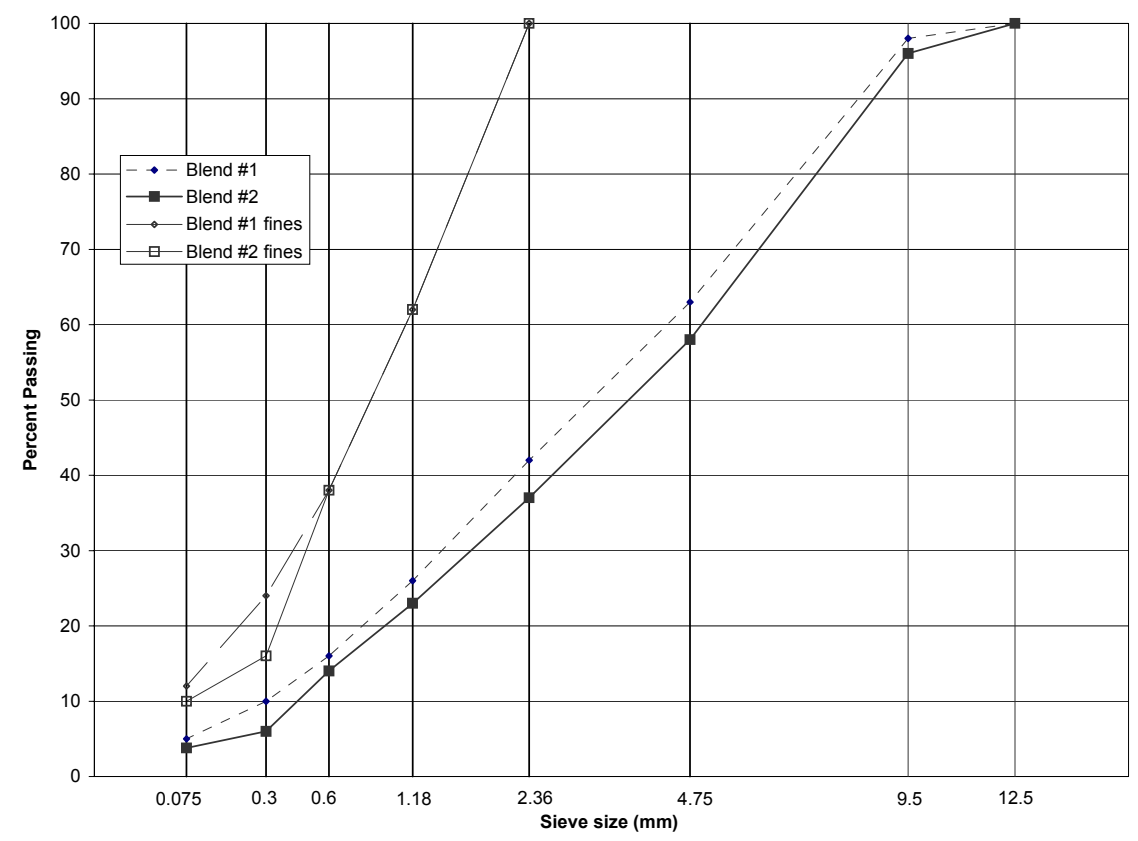

Figure 3.1 Blend gradations

To control the number of variables affecting the experiment, compromises were made in the number of material sources. All asphalt cement used in the experiments was a PG 70-22 donated by Marathon-Ashland. JF Allen was the source for all limestone aggregates. All coarse material, retained on the $4.75 \mathrm{~mm}$ sieve, was from their \# 8 stockpile. All of the fine limestone aggregate was from a single JF Allen fine aggregate stockpile. The dolomite and natural sand were supplied by West Virginia Paving. 
The combination of factors and levels examined during the experiment are:

\begin{tabular}{|l|l|}
\hline Factors & Levels \\
\hline Asphalt content & $5.2,5.7,6.7$ percent \\
\hline Coarse aggregate & Blend $\# 1$ and Blend $\# 2$ \\
\hline $\begin{array}{l}\text { Fine aggregate (percent of the fine aggregate } \\
\text { that is crushed limestone) }\end{array}$ & $100,75,50,25,0$ \\
\hline
\end{tabular}

There were 10 combinations of aggregate factors. For each combination of aggregates, the following testing schedule was performed:

- Fine aggregate angularity, three replicates

- CAR resistance, 6 replicates

There are 30 combinations of factors and levels tested during the experiment. All combinations were tested. Tests performed were:

- Maximum theoretical specific gravity, one per combination

- Bulk specific gravity of samples compacted to 100 gyrations, two specimens per combination

- Asphalt pavement analyzer specimens compacted to $75 \mathrm{~mm}$ with void contents of $7 \pm$ 0.5 percent, six specimens per combination.

\subsection{AGGREGATE PREPARATION}

After the aggregates were collected from the supplier, they were air dried, sieved (ASTM C136, 1984), washed, oven dried and stored in segregated bins. The aggregate preparation for both mix designs were the same. The crushed limestone and dolomite were stored in three bins with materials retained on the 9.5, 4.75 and $2.36 \mathrm{~mm}$ sieves, respectively. The minor amount of material from the coarse stockpiles which passed the $2.36 \mathrm{~mm}$ sieve was discarded. The fine aggregates were separated into four separate bins for each type of aggregate retained on the 1.18, 0.6, 0.3, and $0.075 \mathrm{~mm}$ sieves. The minor amount material from the fine aggregate stockpiles retained on the $2.36 \mathrm{~mm}$ sieve was discarded. The decision to separate the coarse and fine materials based on the 
$2.36 \mathrm{~mm}$ sieve is an artifact of the preliminary CAR testing protocol which specified the test was to be performed on material finer than $2.36 \mathrm{~mm}$.

\subsection{PREPARATION}

Weigh-out tables were prepared for each specimen. The required amount of aggregates were placed in a pan and heated to the compaction temperature for the asphalt cement. The asphalt cement was heated to the same temperature. A Kol five-gallon bucket mixer was used to prepare all compaction samples following the procedures developed by Zaniewski and Hughes (2003). The bucket and paddle were heated. The aggregates were added to the bucket and the required asphalt was added. The material was mixed until a uniform coating of the aggregate was achieved. The material was then transferred to a pan, then placed in an oven set at the mixing temperature for two hours. The material was stirred every 30 minutes. After curing, the compaction samples were transferred to the gyratory mold. The appropriate compaction was applied; 100 gyrations for the specimens used for volumetric analysis, and compaction to a height of $75 \mathrm{~mm}$ for the APA samples.

The procedure for mixing the theoretical maximum specific gravity samples was similar, except the samples were hand mixed with the bowl resting in a heated sand bath.

\subsection{VOLUMETRIC ANALYSIS}

The bulk specific gravity samples were compacted with the Superpave gyratory compactor to $\mathrm{N}_{\text {design }}$ of 100 gyrations (AASHTO T166, 2000). Two specimens were prepared for each experimental combination. The volumetric properties of the mixes were evaluated using the average specimen values. A maximum theoretical specific gravity test (AASHTO T209, 1999) was performed for each combination. The bulk specific gravity and maximum specific gravity from the tests were used to evaluate the volumetric properties of the mix using Equations 3.1 to 3.8 (Roberts, et al, 1996).

$$
\% G_{m m, N d e s}=\frac{G_{m b}}{G_{m m}}
$$




$$
\begin{aligned}
& G_{s e}=\frac{1-P_{b}}{\frac{1}{G_{m m}}-\frac{P_{b}}{G_{b}}} \\
& P_{b a}=100\left(\frac{G_{s e}-G_{s b}}{G_{s b}\left(G_{s e}\right)} G_{b}\right) \\
& P_{b e}=P_{b}-P_{b a}\left(1-P_{b}\right) \\
& \frac{d}{B}=\frac{\% P_{\# 200}}{P_{b e}} \\
& V T M=1-\frac{G_{m b}}{G_{m m}} \\
& V M A=100\left(1-\frac{G_{m b}\left(1-P_{b}\right)}{G_{s b}}\right) \\
& V F A=100\left(\frac{V M A-V T M}{V M A}\right)
\end{aligned}
$$

where,

$\% \mathrm{G}_{\mathrm{mm}, \mathrm{Ndes}}=$ Percent of maximum specific gravity at design number of revolutions;

$\mathrm{G}_{\mathrm{mb}}=$ Bulk specific gravity;

$\mathrm{G}_{\mathrm{mm}}=$ Maximum specific gravity;

$\mathrm{G}_{\mathrm{se}}=$ Effective specific gravity of aggregate;

$\mathrm{P}_{\mathrm{b}}=$ Percent binder;

$\mathrm{G}_{\mathrm{b}}=$ Specific gravity of the binder;

$\mathrm{P}_{\mathrm{ba}}=$ Percent binder absorbed;

$\mathrm{G}_{\mathrm{sb}}=$ Bulk specific gravity of aggregate;

$\mathrm{P}_{\mathrm{be}}=$ Effective percent binder 
$\% \mathrm{P}_{\# 200}=$ Percent of the aggregate blend passing the $\# 200$ sieve;

$\% \mathrm{G}_{\mathrm{mm}, \mathrm{Nini}}=$ Percent of maximum specific gravity at initial number of revolutions;

$\mathrm{h}_{\text {des }}=$ Height at the design number of revolutions;

$\mathrm{h}_{\text {ini }}=$ Height at the initial number of revolutions;

$\mathrm{VTM}=$ Air voids in compacted mixture;

$\mathrm{VMA}=$ Volume of voids in mineral aggregates; and

$\mathrm{VFA}=$ Voids filled with asphalt

Equation 3.6 was also used to compute the voids content of the APA samples.

\subsection{ASPHALT PAVEMENT ANALYZER}

A Pavement Technology Inc. Asphalt Pavement Analyzer, Figure 3.2, was used to evaluate the rutting potential of each mix. The utility and operation of this device is welldocumented in the literature (Skok, et al, 2002, Zaniewski and Nelson, 2003, Zaniewski and Nallamothu, 2003, and Mohammad, et al, 2002).

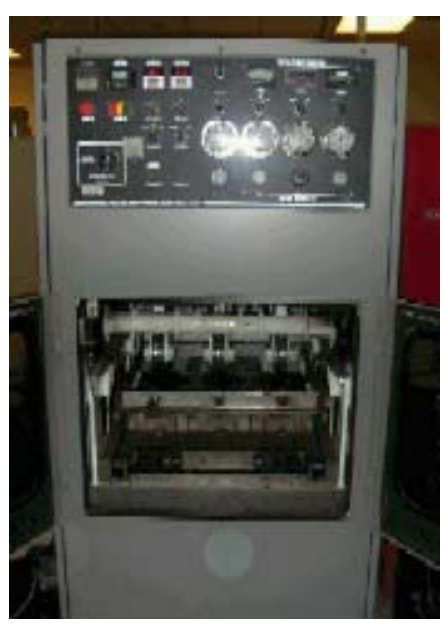

Figure 3.2 Asphalt pavement analyzer

Asphalt Pavement Analyzer (APA) specimens were made using the Superpave Gyratory compactor. These specimens were compacted to a height of $75 \mathrm{~mm}$ without 
constraining the number of gyrations needed to achieve the required height. Specimens for the APA were rejected if the void content was outside the range of $7 \pm 0.5$ percent and replacement specimens were made. All tests were performed at a temperature of $60^{\circ} \mathrm{C}$. The contact tubes were pressurized to $100 \mathrm{psi}$, and 8,000 applications of the $100 \mathrm{lb}$. wheel load were applied. After APA testing, the rut depth was measured at two points equally spaced across the specimen to determine the average rut depth for the sample. West Virginia University uses an electronic Mitutoya Digimatic Indicator to measure the rut depth of the specimen up to $13.66 \mathrm{~mm}$ in depth. However, during this project there were much higher rut depths. A simple measuring device, shown in Figure 3.3, was fabricated to measure the needed rut depths. The point of the measuring rod was placed at the lowest point of the rut, and then marked at the top edge of the aluminum bridge; the rod was then measured accordingly to the nearest half millimeter. This value, minus the height of the bridge, is the rut depth.

The APA has six loading positions for cylindrical specimens. During each run of the machine, the six specimens tested were for one experimental combination as defined in the design of the experiment section. The rut depth for an experimental combination was determined as the average of the rut depth for each specimen.

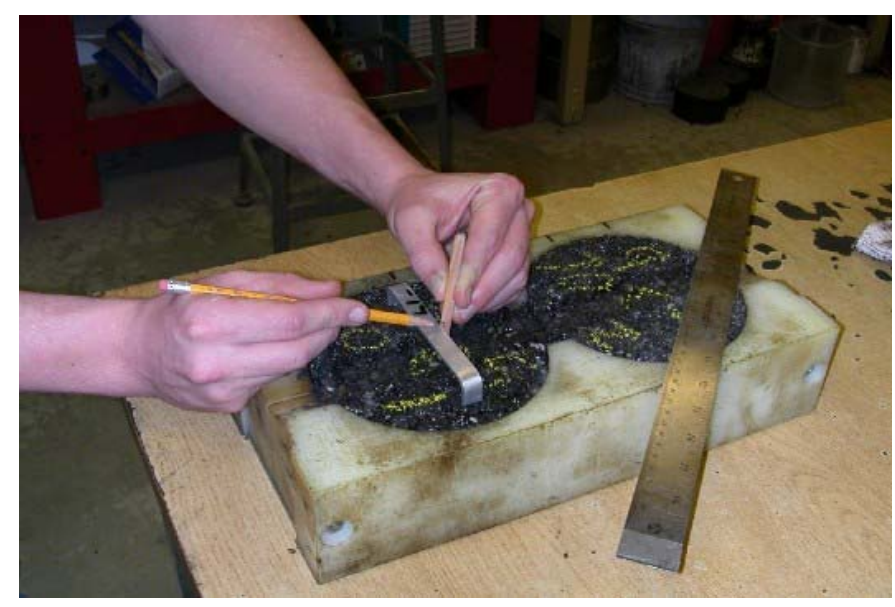

Figure 3.3 Measuring system for APA specimens 


\subsection{FINE AGGREGATE ANGULARITY TESTS}

The Fine Aggregate Angularity test ASTM C-1252 was performed on the crushed limestone and natural sand fine aggregate. The FAA values for blends of the aggregates were computed using a weighted average equation. Zaniewski and Nelson (2003) have demonstrated that the weighted average equation produces results that are equal to the values obtained by blending the aggregates and measuring the FAA. Table 3.2 presents the FAA results from Zaniewski and Nelson (2003). These results were from the same stockpile of materials as used in this research, therefore, there values were used in subsequent comparative analyses with the CAR results.

Table 3.2 Results of Fine Aggregate Angularity

\begin{tabular}{|l|c|c|c|}
\hline $\begin{array}{l}\text { Blend } \\
\text { (LS/NS) }\end{array}$ & $\begin{array}{c}\text { Specific } \\
\text { Gravity }\end{array}$ & $\begin{array}{c}\text { Test Results } \\
\text { Uncompacted } \\
\text { Voids (percent) }\end{array}$ & $\begin{array}{c}\text { Computed Results } \\
\text { Uncompacted } \\
\text { Voids(percent) }\end{array}$ \\
\hline $100 / 0$ & 2.618 & 43.5 & - \\
\hline $75 / 25$ & 2.596 & 42.5 & 42.5 \\
\hline $50 / 50$ & 2.575 & 41.2 & 41.5 \\
\hline $25 / 75$ & 2.554 & 40.2 & 40.4 \\
\hline $0 / 100$ & 2.534 & 39.4 & - \\
\hline
\end{tabular}

\subsection{CAR TEST}

The Compacted Aggregate Resistance test is in the developmental stage. The testing protocol available at the time of this research was used as a guideline for the blends of fine aggregates. The testing protocol used is presented in Appendix B. The samples were prepared to the gradations used for the mix designs using only the material passing the $2.36 \mathrm{~mm}$ sieve. The moisture content of the specimens was 3.5 percent. The samples were compacted using a Pine Automatic Marshall compactor using 50 blows on one side of the sample. A Pine stabilometer, with a special loading head as shown in Figure 2.2, was used to measure the CAR force values for each specimen. Figure 2.3 presents typical results from the CAR test. Ideally the CAR force should be the 
maximum value for punching shear resistance for a material. However, the peak force on some samples was not achieved within the deformation measurements capability of the Marshall data recorder. In these cases, the CAR force was measured at 0.25 inch of deformation. Six specimens were prepared and tested for each blend of fine aggregates. The average of the six results was used as the CAR value for the subsequent analysis. 


\section{CHAPTER 4 RESULTS AND ANALYSIS}

\subsection{INTRODUCTION}

Samples were prepared and tested in accordance with the experimental design presented in the previous chapter. All work was performed in the Asphalt Technology Laboratory at West Virginia University. The CAR force and APA rutting potential data were collected during this research. The FAA tests had been performed on these aggregates in a previous research project (Zaniewski and Nelson, 2003).

\subsection{AGGREGATE EVALUATION}

\subsubsection{CAR Results}

Plots of the individual CAR test results are presented in Appendix C. The results of the CAR test are summarized in Table 4.1. As shown in Table 4.1, the fine aggregates in blend design $\# 2$ had greater resistance than blend design $\# 1$. This demonstrates an effect of gradation on the CAR results. Even though the difference in the gradations are relatively minor, the CAR test consistently identified Blend $\# 2$, the slightly coarser mix, as having more shear resistance.

For each combination of aggregates, six replicate CAR tests were performed. Seven of the ten tests showed good repeatability with the coefficient of variation being less than ten percent. In consistent test results, with a coefficient of variation greater than ten percent were obtained when 100 percent natural sand was used in the mix. The blend \#1 mix with 75 percent sand had one test result which was out of line with the other results, shown in bold in Table 4.1. This value is less than the mean result minus two standard deviations. Therefore this result was treated as an outlier and removed from the analysis. Blend \#2 with 100 percent fine aggregate had a coefficient of variation of 31.5 percent, shown in bold in Table 4.1. This amount of variation is out of line compared to the other results. The source for variability was not discovered. Jahn (2004b) reported experience with high variability, and that it could be attributed to dust and dirt on the shaft of the Marshall hammer, inhibiting the compactive effort. Since the mean values for the CAR force of this material were reasonable, repeat tests were not performed. 
Table 4.1 Results of CAR test

\begin{tabular}{|c|c|c|c|c|c|c|c|c|c|c|c|}
\hline \multicolumn{12}{|c|}{ Blend Design \#1 Limestone Coarse Aggregate } \\
\hline \multirow{2}{*}{\begin{tabular}{|c|}
$\begin{array}{c}\text { Limestone/ } \\
\text { Natural } \\
\text { Sand }\end{array}$ \\
$100 / 0$
\end{tabular}} & \multirow{2}{*}{\begin{tabular}{|c|}
$\begin{array}{c}\text { Fine } \\
\text { Aggregate } \\
\text { Angularity }\end{array}$ \\
43.5 \\
\end{tabular}} & \multirow{2}{*}{\begin{tabular}{|l|} 
Reading \\
0.25 inch \\
\end{tabular}} & \multicolumn{6}{|c|}{ CAR Force (lbs) } & \multirow{2}{*}{$\begin{array}{l}\text { Avg. } \\
2490.8 \\
\end{array}$} & \multirow{2}{*}{$\begin{array}{c}\text { St. } \\
\text { Dev. } \\
195.5 \\
\end{array}$} & \multirow{2}{*}{$\begin{array}{l}\mathrm{COV} \\
7.8 \% \\
\end{array}$} \\
\hline & & & 2220 & 2775 & 2550 & 2350 & 2450 & 2600 & & & \\
\hline $75 / 25$ & 42.5 & 0.25 inch & 1950 & 2050 & 1925 & 2200 & 2025 & 1900 & 2008.3 & 110.3 & $5.5 \%$ \\
\hline $50 / 50$ & 41.2 & 0.25 inch & 1640 & 1650 & 1690 & 1790 & 1740 & 1690 & 1700.0 & 56.6 & $3.3 \%$ \\
\hline $25 / 75$ & 40.2 & At Peak & 1400 & 700 & 1275 & 1525 & 1490 & 1475 & 1433.0 & 238.2 & $16.6 \%$ \\
\hline $0 / 100$ & 39.4 & At Peak & 775 & 875 & 925 & 775 & 910 & 1025 & 880.8 & 95.9 & $10.9 \%$ \\
\hline \multicolumn{12}{|c|}{ Blend Design \#2 Limestone/Dolomite Coarse Aggregate (50/50) } \\
\hline $\begin{array}{c}\text { Limestone/ } \\
\text { Natural } \\
\text { Sand } \\
\end{array}$ & $\begin{array}{c}\text { Fine } \\
\text { Aggregate } \\
\text { Angularity }\end{array}$ & Reading & \multicolumn{6}{|c|}{ CAR Force (lbs) } & Avg. & $\begin{array}{c}\text { St. } \\
\text { Dev. }\end{array}$ & $\mathrm{COV}$ \\
\hline $100 / 0$ & 43.5 & 0.25 inch & 3450 & 3600 & 3525 & 3800 & 3725 & 3650 & 3625 & 128.5 & $3.5 \%$ \\
\hline $75 / 25$ & 42.5 & 0.25 inch & 3250 & 3400 & 3425 & 3350 & 3350 & 3425 & 3366.7 & 66.5 & $2.0 \%$ \\
\hline $50 / 50$ & 41.2 & 0.25 inch & 2550 & 2550 & 2575 & 2550 & 2610 & 2775 & 2601.7 & 88.1 & $3.4 \%$ \\
\hline $25 / 75$ & 40.2 & At Peak & 1500 & 1390 & 1400 & 1400 & 1425 & 1400 & 1419.2 & 41.3 & $2.9 \%$ \\
\hline $0 / 100$ & 39.4 & At Peak & 440 & 525 & 800 & 990 & 1000 & 960 & 785.8 & 247.3 & $31.5 \%$ \\
\hline
\end{tabular}


Figure 4.1 shows the effect of sand on the CAR force for each of the blends. In both Table 4.1 and Figure 4.1, the ratio of limestone to natural sand is based on the material that is finer than the 2.36 sieve. For example, the rows in Table 4.1, identified as $75 / 25$, indicate that 75 percent of the material finer than the $4.75 \mathrm{~mm}$ sieve is limestone and 25 percent is sand. When the natural sand percentages were above $50 \%$, the CAR force reached peak values prior to 0.25 inches of penetration. When the percentage of crushed limestone was $50 \%$ of the mix and greater a peak force was not identified so the readings were taken at 0.25 inches of penetration. As expected, the greater the crushed limestone in the mix, the greater the CAR force. Figure 4.1 demonstrates an increase in the resistance to deformation as the percent of limestone fine aggregate increases. However, the results vary depending on the gradation of the blends. Blend \#1 has a fairly linear relationship between the CAR results and the percent of limestone. Blend \#2 indicates a nonlinear effect of the percent limestone. The results for the two gradations were similar for 0 and 25 percent limestone. When limestone percent was greater than 50 percent, Blend \#2 has higher CAR force than Blend \#1. The only difference between Blends \#1 and \#2 was a minor change in gradation as shown in Figure 3.1.

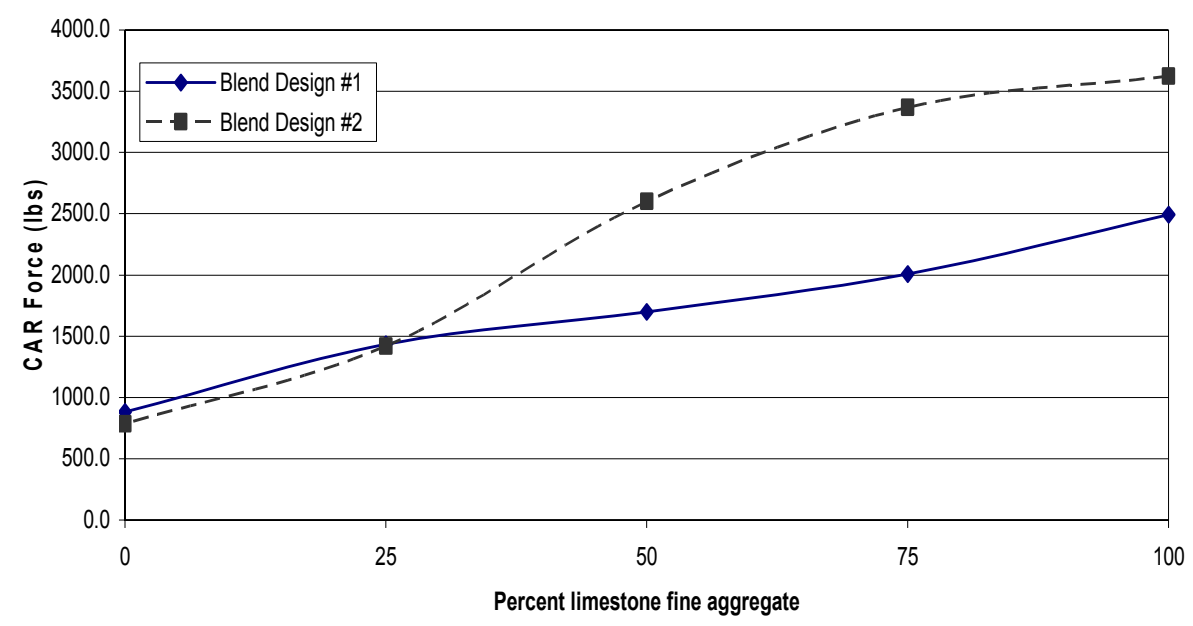

Figure 4.1 Effect of percent limestone on CAR force 


\subsubsection{Fine Aggregate Angularity Results}

Figure 4.2 shows the FAA increasing as the percent of limestone in the fine aggregate increases, similar to the CAR results. Since the FAA is performed on a specified gradation, it is not capable of identifying the effect of gradation. The FAA test procedure does permit altering the gradations. However, this is not the method required by the Superpave specifications so this alternate method for preparing the samples was not evaluated during this research. It was observed that the FAA for the crushed limestone samples was 43.5 percent air voids. This is less than the Superpave requirement of $\mathrm{FAA} \geq 45$ for high volume traffic design.

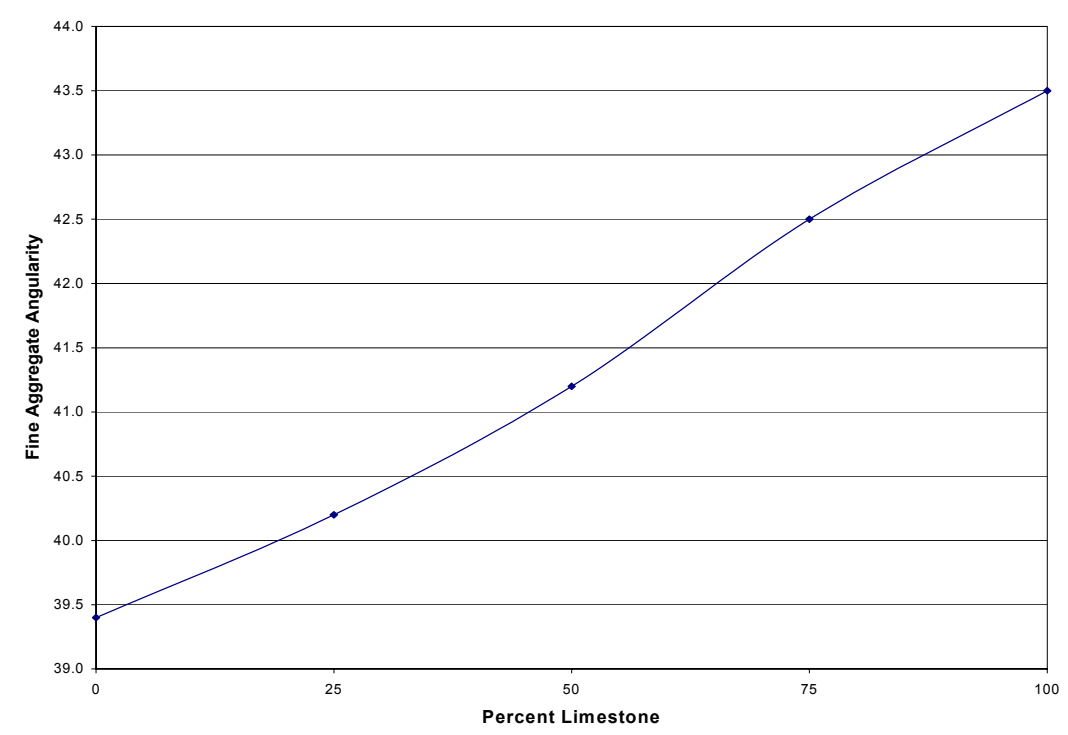

Figure 4.2 Fine Aggregate Angularity Results.

\subsubsection{Comparison of CAR and FAA}

Comparison of Figures 4.1 and 4.2 demonstrate a significant weakness of the Fine Aggregate Angularity test. Under the current Superpave specifications, the FAA test is not capable of distinguishing the effect of gradation on the internal friction produced between the fine aggregates. The CAR test appears to overcome this flaw.

\subsubsection{Evaluations and comparison with other studies}

The only other source of CAR test results were presented by Jahn (2003). These results demonstrated the sensitivity of the CAR force to aggregate type. Other than 
general trends with respect to aggregate type, there are no specific results that can be compared to the results of this research. As with this research, Jahn found that crushed materials performed better than natural sands. Jahn does not report on tests or experiments that would permit the development of a specification for the results from the CAR test.

\subsection{RUTTING RESULTS AND ANALYSIS}

Table 4.2 shows the average rut potential values for the different combination of the experiment. Figure 4.3 shows as positive correlation between rutting potential, the asphalt content, blend type, and percent of natural sand. Blend \#2 has a coarser gradation than Blend \#1, providing a greater resistance to the APA wheel load.

Figures 4.4 and 4.5 show the relationship between the CAR properties of the fine aggregates compared to rutting potential for Blend \#1 and Blend \#2. Each graph shows the percentages of limestone used in the CAR experiment and the rut depth of the sample corresponding to that blend of fine aggregate. The CAR properties are based solely on the gradation of fine aggregates passing the $2.36 \mathrm{~mm}$ sieve, compared to the APA samples that are based on aggregates passing the $12.5 \mathrm{~mm}$ sieve, with the same gradations, respectively, and varying the percentage of asphalt content. The correlation coefficients for the CAR force and the rutting potential were computed for each combination of blends and asphalt contents. As would be expected from inspection of Figures 4.4 and 4.5, there is a high degree of correlation between CAR force and rutting potential. The correlation coefficients ranged from -0.89 to -0.99 .

Figure 4.3 shows the rutting potential for Blend \#1 with asphalt contents of 5.2, 5.7, and 6.7 percent. The CAR test evaluates fine aggregate; therefore asphalt binder plays no role in the CAR results. However, Figure 4.4 demonstrates that the correlation between the CAR force and rutting potential is consistent with asphalt contents, as would be expected. For example, the 50/50 blend of fine aggregates, with a CAR force of 1700 $1 \mathrm{bs}$, the rut potential Blend $\# 1$ at 5.2, 5.7, and 6.7 percent asphalt content is 9.46, 11.88, and $18.00 \mathrm{~mm}$ respectively. As shown on Figure 4.5, similar results were found for Blend \#2. 
Table 4.2 Results of rutting potential tests with the APA

\begin{tabular}{|c|c|c|c|}
\hline \multicolumn{4}{|c|}{ Blend \#1. Limestone Coarse Aggregate } \\
\hline $\begin{array}{l}\text { Asphalt Content } \\
(\%)\end{array}$ & $\begin{array}{l}\text { Limestone/Natural sand } \\
\text { Fine Aggregate }\end{array}$ & $\begin{array}{l}\text { Avg. Rut Depth } \\
(\mathrm{mm})\end{array}$ & St. Dev. \\
\hline \multirow[t]{5}{*}{5.2} & $100 / 0$ & 7.25 & 1.67 \\
\hline & $75 / 25$ & 7.46 & 1.08 \\
\hline & $50 / 50$ & 9.46 & 1.48 \\
\hline & $25 / 75$ & 9.75 & 0.87 \\
\hline & $0 / 100$ & 15.75 & 2.73 \\
\hline \multirow[t]{5}{*}{5.7} & $100 / 0$ & 7.50 & 1.43 \\
\hline & $75 / 25$ & 9.42 & 1.58 \\
\hline & $50 / 50$ & 11.88 & 2.15 \\
\hline & $25 / 75$ & 12.67 & 1.70 \\
\hline & $0 / 100$ & 16.38 & 3.35 \\
\hline \multirow[t]{5}{*}{6.7} & $100 / 0$ & 14.58 & 4.25 \\
\hline & $75 / 25$ & 16.50 & 2.00 \\
\hline & $50 / 50$ & 18.00 & 2.39 \\
\hline & $25 / 75$ & 21.54 & 2.63 \\
\hline & $0 / 100$ & 23.17 & 2.08 \\
\hline \multicolumn{4}{|c|}{ Blend \#2. Limestone/Dolomite (50/50) Coarse Aggregate } \\
\hline $\begin{array}{l}\text { Asphalt Content } \\
(\%)\end{array}$ & $\begin{array}{l}\text { Limestone/Natural sand } \\
\text { Fine Aggregate }\end{array}$ & $\begin{array}{l}\text { Avg. Rut Depth } \\
(\mathrm{mm})\end{array}$ & St. Dev \\
\hline \multirow[t]{5}{*}{5.2} & $100 / 0$ & 5.96 & 1.53 \\
\hline & $75 / 25$ & 7.58 & 1.44 \\
\hline & $50 / 50$ & 8.21 & 1.21 \\
\hline & $25 / 75$ & 8.71 & 1.10 \\
\hline & $0 / 100$ & 9.83 & 2.43 \\
\hline \multirow[t]{5}{*}{5.7} & $100 / 0$ & 6.96 & 0.81 \\
\hline & $75 / 25$ & 7.96 & 1.25 \\
\hline & $50 / 50$ & 9.46 & 1.16 \\
\hline & $25 / 75$ & 9.88 & 1.15 \\
\hline & $0 / 100$ & 11.67 & 1.64 \\
\hline \multirow[t]{5}{*}{6.7} & $100 / 0$ & 8.00 & 1.15 \\
\hline & $75 / 25$ & 10.29 & 1.76 \\
\hline & $50 / 50$ & 12.25 & 1.59 \\
\hline & $25 / 75$ & 16.08 & 4.03 \\
\hline & $0 / 100$ & 17.54 & 1.80 \\
\hline
\end{tabular}




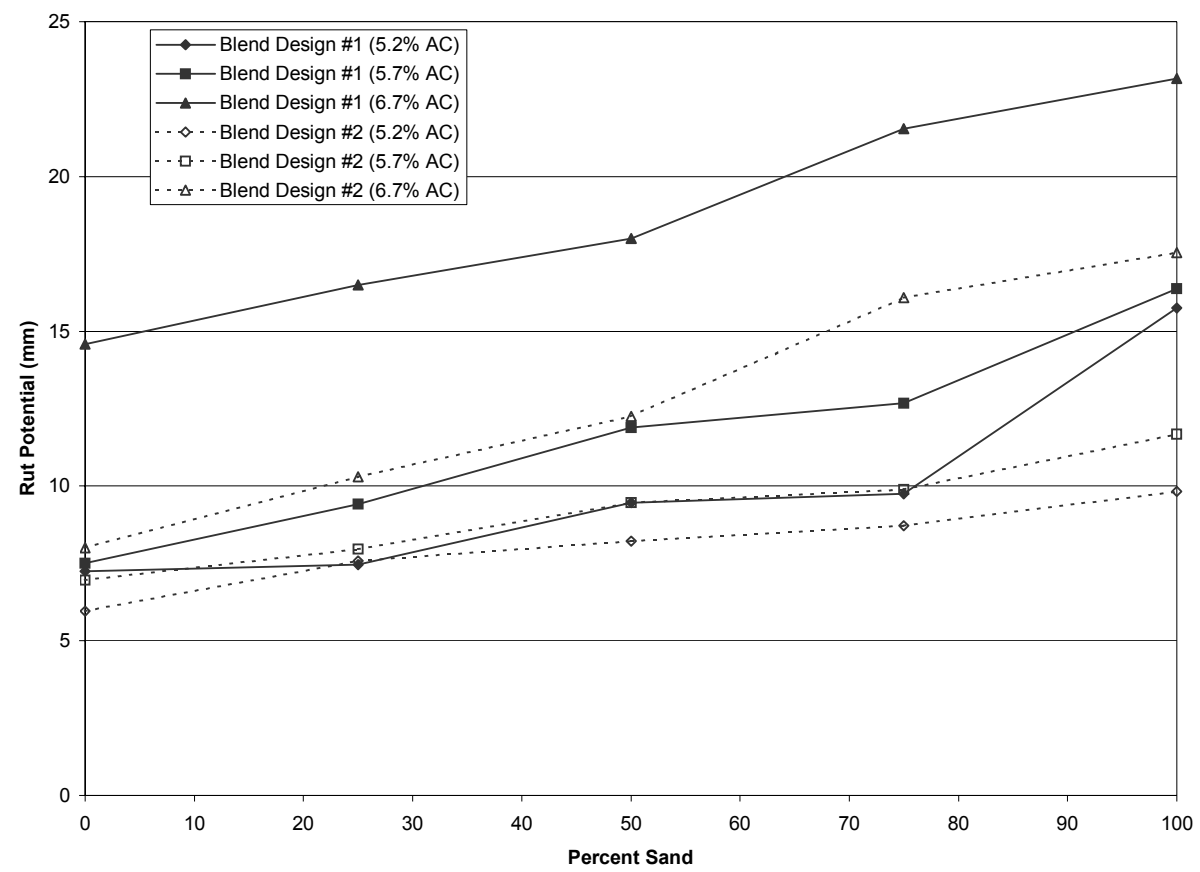

Figure 4.3 Effect of asphalt content, blend types and percent sand on rutting potential

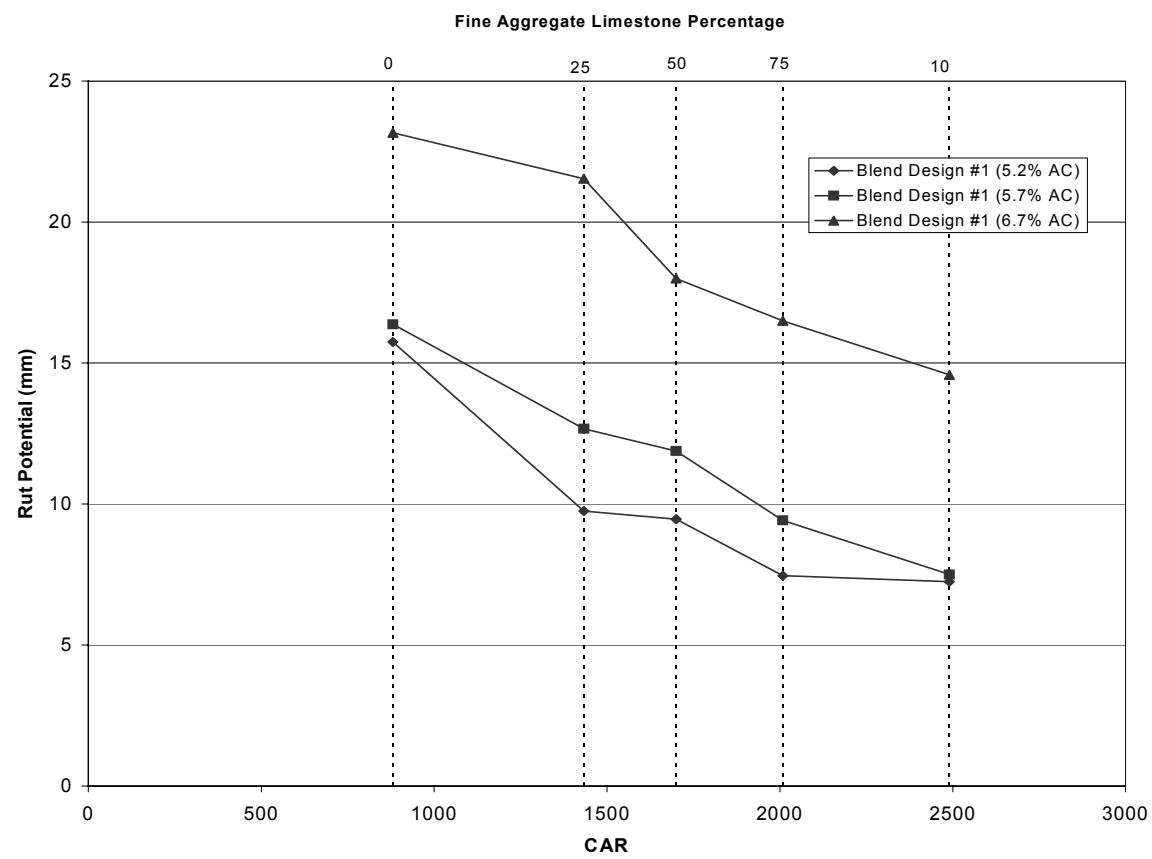

Figure 4.4 Relationship between CAR force and rutting potential for Blend \#1 


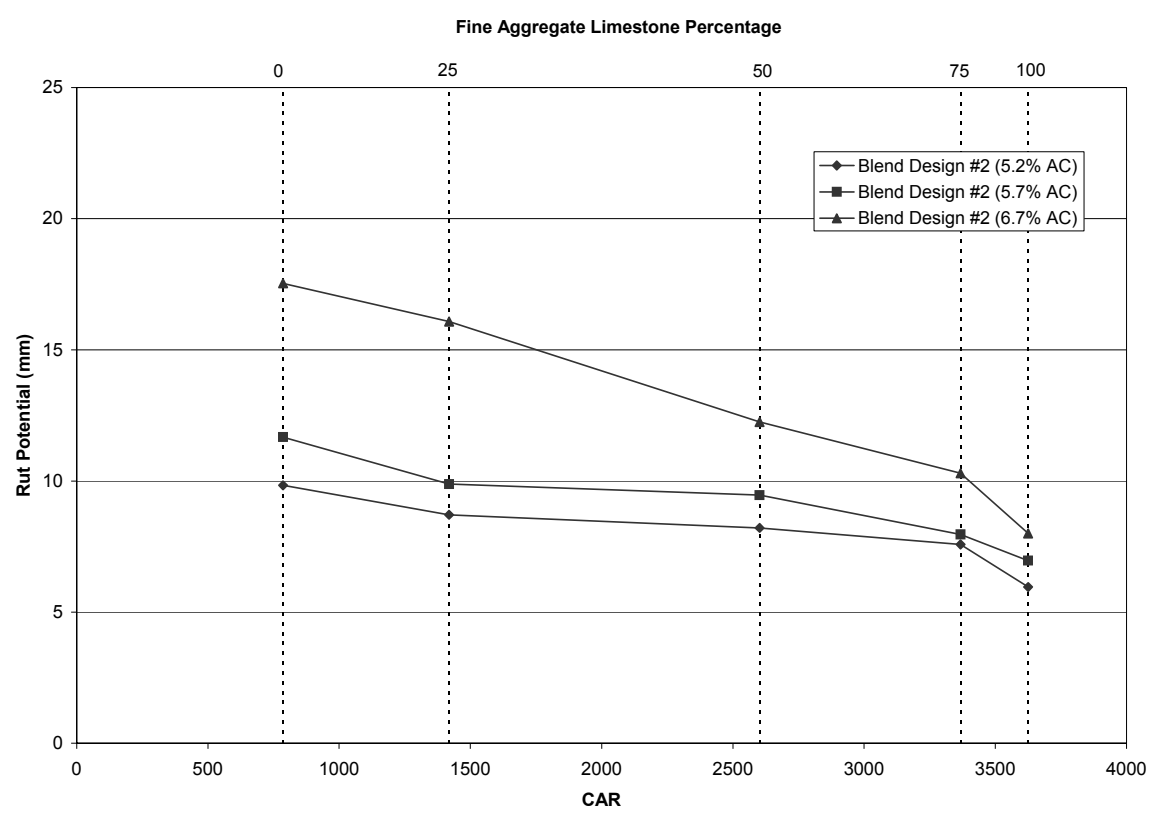

Figure 4.5 Relationship between CAR force and rutting potential for Blend \#2

The strong correlation between the CAR force and rutting potential is encouraging. However, it should be noted that the Georgia criterion for acceptable rutting potential is $6 \mathrm{~mm}$. Under this criterion, the only mix tested that meets the criteria is Blend \#2 with 5.2 percent asphalt and 100 percent limestone fine aggregate. Similar criteria have not been developed for West Virginia. However, tests of Superpave $9.5 \mathrm{~mm}$ materials from construction sites across the state indicate that the average rutting potential is $6.3 \mathrm{~mm}$. All of these samples used 100 percent limestone materials, so the evaluation of rutting potential during this project is consistent with experience in the state.

\subsection{SUMMARY OF RESULTS}

The CAR test demonstrated an ability to evaluate a meaningful characteristic of fine aggregates. It is strongly correlated with rutting potential as evaluated by the asphalt pavement analyzer. For all of the mixes evaluated, the CAR and APA results were consistent with engineering expectations, i.e. increasing the natural sand content and asphalt content increases the rutting potential of asphalt concrete. 


\section{CHAPTER 5 CONCLUSIONS AND RECOMMENDATIONS}

\subsection{CONCLUSIONS}

This research project started while the CAR test was in the developmental stage. The CAR tests performed during this project used material passing the $2.36 \mathrm{~mm}$ sieve, blended to have the same proportion of materials on each sieve as is used in a mix design. The current recommendation is to test all the material passing the $4.75 \mathrm{~mm}$ sieve (Jahn, 2003). The influence of how this change in testing protocol affects the results was not evaluated during this research.

Overall, the repeatability of the CAR test was reasonable for the majority of the results, with the coefficient of variation being less than 5 percent. However, the coefficient of variation was more than 10 percent for three of the aggregate combinations. In one case, for Blend \#1 with 75 percent sand, there was an apparent outlier in the data. The other two cases where the coefficient of variation was more than 10 percent occurred for the 100 percent natural sand blends. The reason for the greater degree of variability of the CAR force for the 100 percent sand was not investigated.

The CAR test was able to distinguish the two gradations evaluated during the research, even though there was little difference in the percent of material retained on each sieve as shown on Figure 3.1. This is an advantage over the fine aggregate angularity procedure which uses a defined gradation during the test and is therefore incapable of evaluating the effect of gradation.

Due to the loading limitations of the Marshall stabilometer, it was necessary to use two methods for interpreting the test results. If the peak force on the sample is reached during the test, then the CAR force is equal to the peak force. However, if the sample's resistance to punching shear is greater than the test capability of the machine, then the CAR force is determined as the force required to produce $0.25 \mathrm{in}$. of deformation. For the aggregate blends evaluated, natural sand contents greater than 50 percent, had peak force that could be measured. At lower sand contents, the deformation- 
based method for determining CAR force was required. This methodology could potentially lead to inconsistent results.

Both the CAR and FAA test results correlated with the measured rutting potential of the mixes. However, the CAR test was able to distinguish the effect of gradation, which cannot be evaluated with the FAA test using the Superpave specified protocol.

It should be noted that the quality of fine aggregates is only one factor contributing to the rutting potential of hot mix asphalt concrete. Test results from this project demonstrate the influence of asphalt content. Other factors that contribute to rutting potential include the characteristics and gradation of the coarse aggregates, the voids in the total mix, the type or grade of asphalt cement, etc. While testing the characteristics of fine aggregate may be valid for screening fine aggregates with respect to their contribution to rutting potential, they cannot be used as the sole indicator of the rutting potential of a mix.

A primary objective of this research was to assess the relationship between the CAR test and rutting potential. Ideally, this information would provide insight for the development of a specification for an acceptable limit for CAR results. However, the rutting potential measured for the mixes included in this experiment were in excess of what is generally considered as an acceptable value for rut resistance and mixes. Hence the project did not provide information sought for the development of the specification limit for the CAR test.

\subsection{RECOMMENDATIONS}

The CAR method is still under development and has not been adopted by any highway agency as a means for screening fine aggregates for use in asphalt concrete. Further research is needed to establish the validity of the method. However, the method does produce a measure that is highly correlated with rutting potential. The CAR results appear to have good repeatability, though the weaker mixes appear more sensitive to the shear force. The inconsistent data may be the result of an unrefined experimental procedure. The presentation at ICAR (2003) by David Jahn suggested a few recommendations for reducing variances. 
- Monitor the Marshall hammer so that debris from the compacted aggregate does not transport to the shaft and cause unwanted friction.

- Keep the shaft well-lubricated before every test.

\subsection{FURTHER RESEARCH}

Although the CAR test demonstrated a strong correlation with rutting potential, it should be noted that the CAR results were also well correlated with the FAA results and the percent sand in the mix. This being the case, for the set of materials evaluated during this research, similar results would have been obtained correlating rutting potential with FAA or percent sand. This demonstrates a need to continue to evaluate and develop the CAR test for a broader range of materials.

The issue of using a deformation cutoff criteria for aggregates with a high resistance to punching shear should be resolved if the CAR method is to be used for more than screening aggregates. The need for the deformation cutoff criteria is an artifact of the desire to use a commonly available testing device in lieu of developing a machine specifically for the task. Alternatives could include developing a more powerful Marshall stabilometer, looking at different sample sizes, or possibly reducing the size of the loading head used for the CAR test.

In order to develop limits for acceptable CAR test results, a more robust relationship between CAR results and the rutting potential of a mix needs to be established. The research presented herein demonstrates that a relationship exists, but the data set was not adequate for defining a performance limit. More research is required, especially with mixes that have low rutting potential, to establish limits for the CAR results. 


\section{REFERENCES}

1. Barker L.R., Materials Division, WVDOH, phone communications with John Zaniewski, 2003.

2. Chowdury A., Button J.W., Kohale V., and D.W. Jahn, Evaluation of Superpave Fine Aggregate Angularity Specification, Report No. 4040111, International Center for Aggregate Research, Austin, TX, 2001.

3. Harman T., D’Angelo J., and J. Bukowski, Superpave Asphalt MixtureDesign. Workshop Version 8.0, Federal Highway Administration, Washington D.C., January 2002.

4. Jahn D.W., Compacted Aggregate Resistance Test, Presentation at ICAR, May 2003.

5. Jahn D.W., Product Development, Martin Marietta Technologies, electronic mail communications with Sean Rafferty, 2004a.

6. Jahn D.W., Product Development, Martin Marietta Technologies, letter to Sean Rafferty, 2004b.

7. Kandhal, P.S., Investigation of the Restricted Zone in the Superpave Aggregate Gradation Specification, National Cooperative Highway Research Program, NCAT Report No. 9-14, Auburn University, Auburn AL, 1998.

8. Kandhal P.S., and L.A. Cooley, Evaluation of Permanent Deformation of Asphalt Mixtures Using Loaded Wheel Tester, Association of Asphalt Paving Technologists, March 2002.

9. Kandhal P.S., and R.B. Mallick, Evaluation of Asphalt Pavement Analyzer for HMA Design, NCAT Report No. 99-4, June 1999.

10.Marek, C.M., White Paper on Fine Aggregate Angularity, Vulcan Materials Company, Minneapolis, MN, August, 2002.

11.Mohammad L.N., Wu Z., Wang L., and C. Abadie, A Rut Susceptibility Study of Superpave Asphalt Mixtures, Louisiana Transportation Research Center, Baton Rouge, LA, May 2002.

12.Purcell E.M., and S.A. Cross, Effects of Aggregate Angularity on VMA and Rutting of KDOT Superpave Level I Mixes, Kansas Department of Transportation, Topeka, KN, May 2001. 
13.Roberts F.L., Kandhal P.S., Brown E.R., Lee D., and T.W. Kennedy, Hot Mix Asphalt Materials, Mixture Design, and Construction, NAPA Education Foundation, Lanham, MD, 1996.

14. Roque R., Evaluation of SuperpaveTM Criteria for VMA and Fine Aggregate Angularity, Department of Civil and Coastal Engineering, University of Florida, Gainesville, Fl, March 2002.

15.Skok E.L., Turk A., and E. Johnson, Asphalt Pavement Analyzer (APA) Evaluation, Minnesota Department of Transportation, St. Paul, MN, September 2002.

16.Stakston A.D., Hussain B.U., and J.J. Bushek, Effect of Fine Aggregate Angularity on Compaction and Shearing Resistance of Asphalt Mixtures, Transportation Research Record 1789, pp. 14-22, 2002.

17. White T., Effects of Fine Aggregate Angularity on Asphalt Mixture Performance, INDOT Project Number SPR - 2153, Purdue University, IN, December 1998.

18.Zaniewski J.P., and Hughes, Inter Laboratory Variability of the Marshall Test Method for Asphalt Concrete, WVDOH RP \#137, West Virginia University, Morgantown, WV, 2003.

19.Zaniewski J. P., V. Kanneganti, Comparison of $19 \mathrm{~mm}$ Superpave and Marshall Base II Mixes in West Virginia, WVDOH Report, West Virginia University, Morgantown, WV, 2003.

20.Zaniewski J. P., and S.H. Nallamothu, Evaluation of Binder Grades on Rutting Performance, WVDOH Report, West Virginia University, Morgantown, WV, 2003.

21.Zaniewski J.P., and J. Nelson, Comparison of $9.5 \mathrm{~mm}$ Superpave and Marshall Wearing I Mixes in West Virginia, WVDOH Report, West Virginia University, Morgantown, WV, 2003.

\section{Specifications and Test Methods}

1. Plastic Fines in Graded Aggregates and Soils by Use of the Sand Equivalent Test. AASHTO T176, 2000.

2. Uncompacted Void Content of Fine Aggregate, AASHTO T304 (ASTM C-1252), 1996.

3. Test Method for Determining the Percentage of Fractured Particles in Coarse Aggregate, ASTM D5821, 1995. 
4. Test Method for Determining Flat or Elongated Particles in Coarse Aggregate, ASTM D4791, 1999.

5. Specification for Superpave Volumetric Mix Design, AASTHO MP2, 2001.

6. West Virginia Division of Highways Standard Specifications, Charleston, West Virginia, 2000.

7. Test Method for Determining Direct Shear Resistance, ASTM D3080.

8. Resistance to Plastic Flow of Bituminous Mixtures Using Marshall Apparatus. AASHTO T245. 1993.

9. Sieve Analysis, ASTM C136, 1984.

10. Bulk Specific Gravity of Compacted Bituminous Mixtures Using Saturated Surface-Dry Specimens, AASHTO T166, 2000.

11.Theoretical Maximum Specific Gravity and Density of Bituminous Paving Mixtures, AASHTO T209, 1999. 


\section{APPENDIX A \\ WVDOH MIX DESIGNS}

T400

03-00

\section{WEST VIRGINIA DIVISION OF HIGHWAYS PLANT MIX FORMULA FOR HOT-MIX ASPHALT}

\begin{tabular}{|c|c|c|c|}
\hline Report Number: & 1350476 & Date Accepted: & June 4, 2002 \\
\hline HMA Type: & Wearing-1 Skid & HMA Code: & 13967 \\
\hline Producer: & West Virginia Paving & Plant Location: & Dunbar, WV \\
\hline Designed By: & J. Withrow/D. Boggess & Design Lab: & West Virginia Paving, Dunbar, WV \\
\hline Plant Type: & Drum & Plant Make: & Bituma Gencor \\
\hline Plant Code: & W074C & Traffic Type: & Heavy \\
\hline
\end{tabular}

MIX COMPOSITION

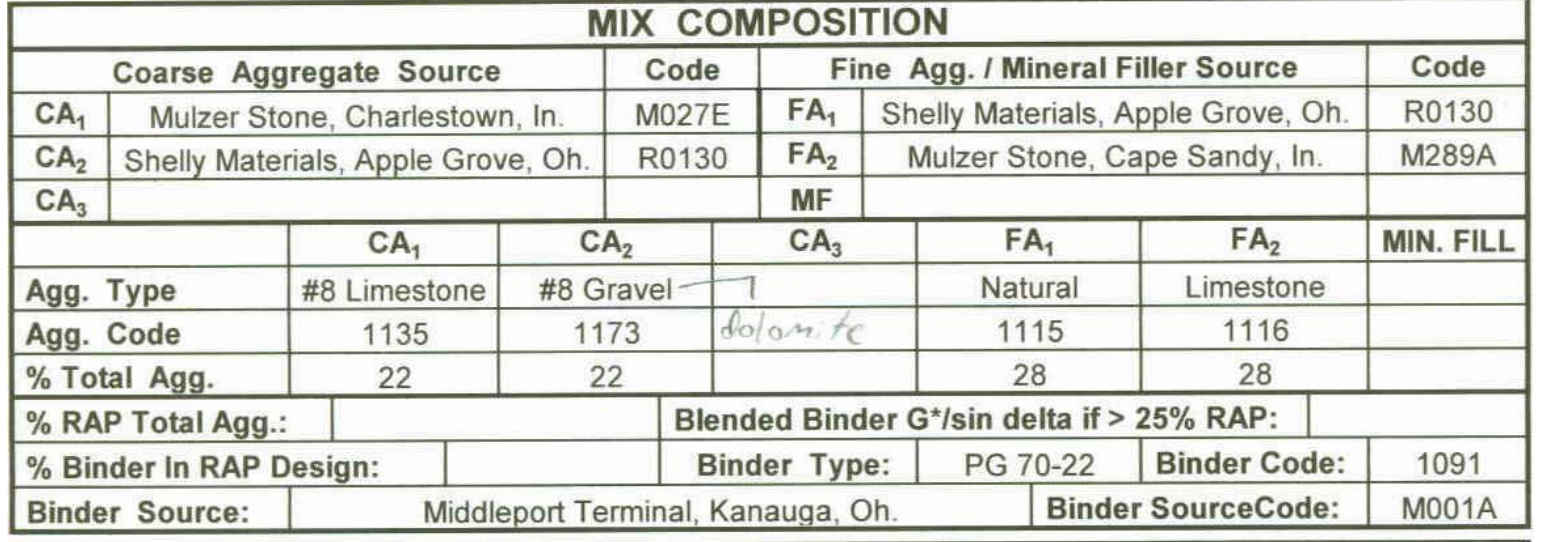

\begin{tabular}{|c|c|c|c|c|c|c|c|c|c|c|}
\hline \multicolumn{8}{|c|}{ Sieve Fraction } & \multirow{3}{*}{$\begin{array}{c}\begin{array}{c}\text { Voids filled with } \\
\text { Asphalt"VFA"(\%) }\end{array} \\
75 \\
\end{array}$} & \multirow{3}{*}{\multicolumn{2}{|c|}{$\begin{array}{c}\begin{array}{c}\text { Fines to } \\
\text { Asphalt Ratio }\end{array} \\
0.6\end{array}$}} \\
\hline Sieve & \multirow[b]{2}{*}{ Target } & \multicolumn{2}{|c|}{ Allowable } & \multirow{2}{*}{\begin{tabular}{|c|}
$\begin{array}{c}\text { Sieve } \\
\text { Size }\end{array}$ \\
\end{tabular}} & \multirow[b]{2}{*}{ Target } & \multicolumn{2}{|c|}{ Allowable } & & & \\
\hline Size & & Min. & Max. & & & Min. & Max. & & & \\
\hline $2 "(50 \mathrm{~mm})$ & & & & $\# 4(4.75 \mathrm{~mm})$ & 58 & & 80 & \multirow{2}{*}{\multicolumn{3}{|c|}{$\begin{array}{c}\text { Temperature Range } \\
\text { Completed Mixture }\left({ }^{\circ} \mathrm{F}\right)\end{array}$}} \\
\hline $1.5^{\prime \prime}(37.5 \mathrm{~mm})$ & & & & $\# 8(2.36 \mathrm{~mm})$ & 37 & 31 & 43 & & & \\
\hline $1^{\prime \prime}(25 \mathrm{~mm})$ & & & & $\# 16(1.18 \mathrm{~mm})$ & 23 & & & \multirow{2}{*}{\begin{tabular}{c|} 
Desirable \\
Mean Temp.
\end{tabular}} & \multicolumn{2}{|c|}{ Temp. Range } \\
\hline $3 / 4^{\prime \prime}(19 \mathrm{~mm})$ & & & & $\# 30(600 \mu \mathrm{m})$ & 14 & & & & Min. & Max. \\
\hline $1 / 2 "(12.5 \mathrm{~mm})$ & 100 & 100 & 100 & $\# 50(300 \mu \mathrm{m})$ & 6 & & & \multirow[b]{2}{*}{313} & \multirow[b]{2}{*}{288} & \multirow[b]{2}{*}{338} \\
\hline $3 / 8^{\prime \prime}(9.5 \mathrm{~mm})$ & 96 & 85 & 100 & $\# 200(75 \mu \mathrm{m})$ & 3.8 & 2.0 & 9.0 & & & \\
\hline
\end{tabular}

\begin{tabular}{|c|c|c|c|c|}
\hline \multicolumn{5}{|c|}{ PLANT MIX FORMULA VALUES } \\
\hline \multicolumn{4}{|c|}{ Plant Mix Formula Targets } & \multicolumn{2}{c|}{ Plant Mix Formula Tolerances } \\
\hline \multirow{2}{*}{$\begin{array}{c}\text { Specific gravity stone } \\
\text { bulk (Gsb): } 2.567\end{array}$} & Design Property & Accepted Target & Minimum & Maximum \\
\cline { 2 - 5 } & Asphalt (\%) & 6.3 & 5.9 & 6.7 \\
\hline Maximum & Air Voids (\%) & 4.0 & 2.5 & 5.5 \\
\cline { 2 - 5 } Density (kg/m ${ }^{3}$ ) & VMA (\%) & 15.9 & 14.9 & 16.9 \\
\hline \multirow{2}{*}{2401} & Stability (N) & 10945 & 8000 & NA \\
\cline { 2 - 5 } & Flow (0.25mm) & 8 & 8 & 14 \\
\hline
\end{tabular}

Remarks: 
WEST VIRGINIA DIVISION OF HIGHWAYS JOB MIX FORMULA FOR SUPERPAVE HOT-MIX ASPHALT

\begin{tabular}{|c|c|c|c|}
\hline Report Number: & 1349538 & Date Accepted: & May 6,2002 \\
\hline HMA Type: - & $9.5 \mathrm{~mm}$ (Wearing-1) Skid & HMA Code: & 13967 \\
\hline Producer: & J.F. Allen & Plant Location: & Lorentz, WV \\
\hline Designed By: & David Woods & Design Lab: & J. F. Allen - Lorentz, WV \\
\hline Plant Type: & Batch & Plant Make: & McCarter \\
\hline Plant Code: & $\mathrm{A} 007 \mathrm{C}$ & Design ESALs: & $3<30$ Million \\
\hline
\end{tabular}

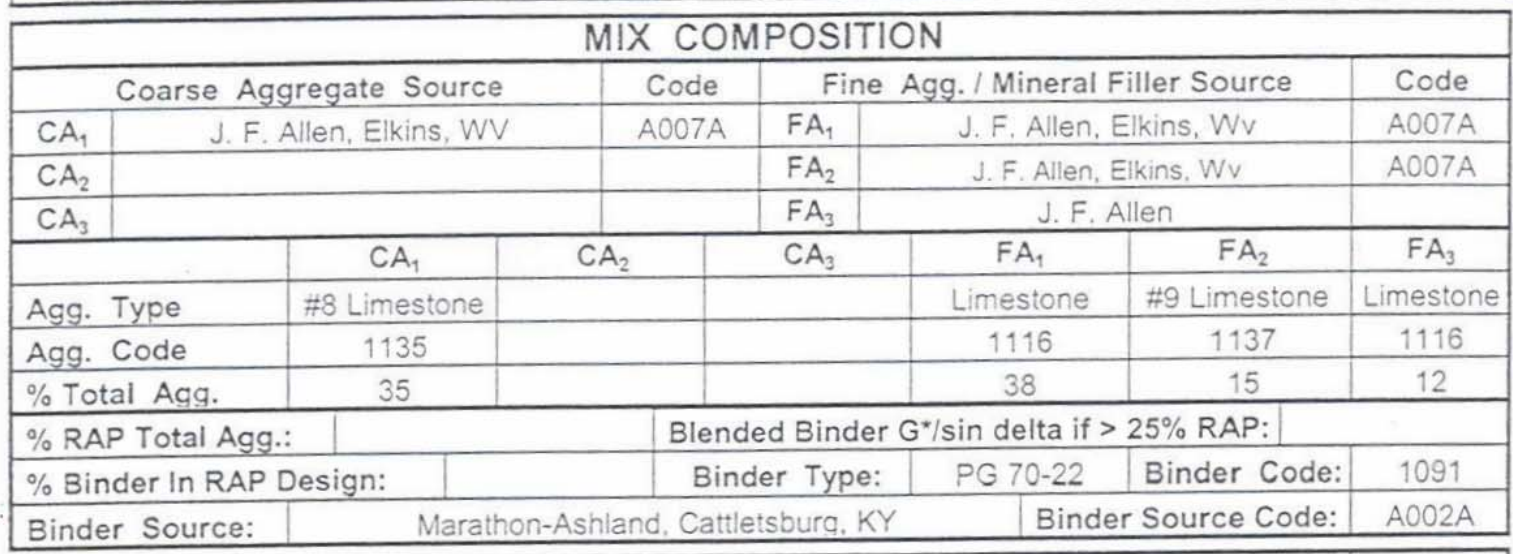

\begin{tabular}{|c|c|c|c|c|c|c|c|c|c|c|c|}
\hline \multicolumn{8}{|c|}{ Sieve Fraction } & \multirow{2}{*}{\multicolumn{2}{|c|}{$\begin{array}{c}\text { Fines / Effective } \\
\text { Asphalt Ratio }\end{array}$}} & \multirow{2}{*}{\multicolumn{2}{|c|}{$\begin{array}{r}\text { Tensile } \\
\text { Strn. Ratio } \\
\end{array}$}} \\
\hline \multirow{2}{*}{$\begin{array}{l}\text { Sieve } \\
\text { Size }\end{array}$} & \multirow[b]{2}{*}{ Target } & \multicolumn{2}{|c|}{ Allowable } & \multirow{2}{*}{$\begin{array}{l}\text { Sieve } \\
\text { Size }\end{array}$} & \multirow[b]{2}{*}{ Target } & \multicolumn{2}{|c|}{ Allowable } & & & & \\
\hline & & Min. & Max. & & & Min. & Max. & 1.0 & & & 93.7 \\
\hline 2" $(50 \mathrm{~mm})$ & & & & $\# 4(4.75 \mathrm{~mm})$ & 63 & & 90 & \multirow{2}{*}{\multicolumn{4}{|c|}{$\begin{array}{c}\text { Temperature Range } \\
\text { Completed Mixture }\left({ }^{\circ} \mathrm{F}\right)\end{array}$}} \\
\hline $1.5^{\prime \prime}(37.5 \mathrm{~mm})$ & & & & $\# 8(2.36 \mathrm{~mm})$ & 42 & 36 & 48 & & & & \\
\hline $1^{\prime \prime}(25 \mathrm{~mm})$ & & & & $\# 16(1.18 \mathrm{~mm})$ & 26 & & & \multirow{2}{*}{$\begin{array}{c}\text { Desirable } \\
\text { Mean Temp. }\end{array}$} & \multicolumn{3}{|c|}{ Temp. Range } \\
\hline $3 / 4^{\prime \prime}(19 \mathrm{~mm})$ & & & & $\# 30(600 \mu \mathrm{m})$ & 16 & & & & Mir & & Max. \\
\hline $1 / 2^{\prime \prime}(12.5 \mathrm{~mm})$ & 100 & 100 & 100 & $\# 50(300 \mu \mathrm{m})$ & 10 & & & & & & \\
\hline $3 / 8^{\prime \prime}(9.5 \mathrm{~mm}$ & 98 & 90 & 100 & $\# 200(75 \mu \mathrm{m})$ & 5 & 2 & 10 & 310 & 28 & 35 & 335 \\
\hline
\end{tabular}

\begin{tabular}{|c|c|c|c|c|c|}
\hline \multicolumn{6}{|c|}{ JOB MIX FORMULA VALUES } \\
\hline \multicolumn{3}{|c|}{ Job Mix Formula Targets } & \multicolumn{3}{|c|}{ Job Mix Formula Tolerances } \\
\hline \multirow{2}{*}{$\begin{array}{l}\text { Specific gravity stone } \\
\text { bulk (Gsb): } \quad 2.658\end{array}$} & Design Property & Accepted Target & Minimum & \multicolumn{2}{|c|}{ Maximum } \\
\hline & Asphalt $(\%)$ & 5.7 & 5.3 & \multicolumn{2}{|c|}{6.1} \\
\hline \multirow{2}{*}{$\begin{array}{c}\text { Maximum } \\
\text { Density }\left(\mathrm{kg} / \mathrm{m}^{3}\right)\end{array}$} & Air Voids (\%) & 4.0 & 2.8 & \multicolumn{2}{|c|}{5.2} \\
\hline & $\operatorname{VMA}(\%)$ & 15.5 & 14.5 & \multicolumn{2}{|c|}{16.5} \\
\hline 2491 & VFA $(\%)$ & 74 & 73 & \multicolumn{2}{|c|}{76} \\
\hline Gyrations@ $N_{\text {initial }}$ : & \multicolumn{2}{|c|}{ Gyrations@ $N_{\text {desian }}$ : } & \multicolumn{2}{|c|}{ Gyrations@ $N_{\max }$ : } & 160 \\
\hline
\end{tabular}

Remarks: 


\section{APPENDIX B \\ CAR TESTING PROCEDURE}

This test method was prepared by David Jahn (2003) and is presented here to document the procedures followed during this research.

A test for evaluating the shear resistance of compacted fine aggregate materials in their "as received" condition.

This procedure is intended for use on the combined fine aggregate materials to be used in the paving mixture. The performance of individual components can be judged provided common sense is used. For example, a component with a high fines content may have good shear resistance but could not represent $100 \%$ of the fine aggregate portion of the mix. Some "high fines" materials will exhibit very high shear values.

\section{Equipment Needed}

- Marshall mold with base-plate attached (welded or secured in a permanent manner),

- Marshall mold collar,

- Marshall Compaction Hammer,

- Mixing bowl and utensils,

- Riffle Splitter, Screen Shaker,

- $2.36 \mathrm{~mm}$ (No 8) Sieve,

- Drying Oven,

- Balance (at least 8,000 gram capacity accurate to 0.1 gram),

- Marshall Stability and Flow Machine with Graph Recorder (5,0001b. Graph Paper),

- Loading head, 1.5 inch diameter X 1.5 inch high steel round stock (top and bottom are flat), mounted to the frame used for split tensile testing.

\section{Procedure}

Secure a representative 5,000-6,000 gram sample by riffle splitting. Splitting should be performed at or near SSD (Saturated- Surface Dry) condition to prevent loss of fines.

Sieve this portion to refusal over a $2.36 \mathrm{~mm}$ (No. 8) screen, again, at or near SSD to prevent the loss of fines. A Gilson 2' X 3' screen shaker is recommended. Discard the material retained on the $2.36 \mathrm{~mm}$ (No. 8) sieve ${ }^{1}$.

Oven dry the material finer than the $2.36 \mathrm{~mm}$ (No. 8) sieve to a constant weight at $110 \pm$ $5^{\circ} \mathrm{C}\left(230 \pm 10^{\circ} \mathrm{F}\right)$

Remove from oven and cool the material to ambient temperature.

\footnotetext{
${ }^{1}$ Recently, this requirement has been altered to include all material passing the $4.75 \mathrm{~mm}$ sieve.
} 
Weigh the material to the nearest 0.1 gram.

Add $1.75 \%$ water by dry weight of the sample and mix thoroughly. ${ }^{2}$

Reduce material by riffle splitting or quartering to approximately 1,100 grams as quickly as possible to reduce moisture loss. Record this weight. Remaining prepared material may be used within one hour if kept in a sealed container. Secondary absorption after a period of time may require that the drying procedure be repeated.

Cover the Marshall compaction hammer striking face with cellophane (Saran Wrap) held in place with a rubber band or aluminum foil. This will prevent particles from adhering to the striking face surface and will produce a smooth bearing surface on the compacted specimen.

Place material in 4-inch diameter Marshall mold meeting the requirements of ASTM D 1559. Spade the material with a spatula 15 times around the perimeter and 10 times over the interior. Remove the collar and smooth the surface with the spatula to a slightly rounded shape.

Replace collar and place mold assembly with specimen on the compaction pedestal. Compact specimen using 50 blows from the Marshall hammer. Unlike the Marshall method only one surface of the specimen is to be compacted.

After compaction carefully remove mold assembly from compaction pedestal. Remove collar and measure distance from top of mold to top of specimen. Calculate specimen height. The specimen should be $6.35 \pm 0.318 \mathrm{~cm}(2.5 \pm 0.125$ inches $)$ in height. If specimen does not meet height requirements, discard compacted specimen (use of Marshall stability correction factors has not been verified). Compact a new specimen using remaining prepared material adjusting the amount required to achieve a specimen height of $6.35 \mathrm{~cm}$ (2.5 inches) using the following formula:

Adjusted weight of aggregate $=\frac{(2.5 \mathrm{X} \text { weight of aggregate used })}{(\text { Actual specimen height obtained in inches })}$

Place compacted sample, with base plate and mold still in the upright, vertical position (compacted face up) along with appropriate spacers (to minimize travel) on the Marshall Stability and Flow machine. Place 1.5-inch diameter x 1.5-inch high steel round stock (flat top and bottom) on the center of the compacted specimen and align vertically under the load cell.

Operate Stability and Flow apparatus at 2 inches travel per minute, recording results on $5,0001 b$ scale paper and plot Shear Resistance vs. Penetration (stability vs. flow) on the graph paper. Carry the penetration to $10 \%$ of the compacted specimen thickness (flow value of 25).

Some fine aggregate materials develop high Shear Resistance values and may therefore damage load cells. The test should be terminated before damage occurs.

\footnotetext{
${ }^{2}$ The moisture content for the samples has been increased to 3.5 percent, which is the value used for the samples prepared and tested during this research.
} 
APPENDIX C

CAR TEST OUTPUT

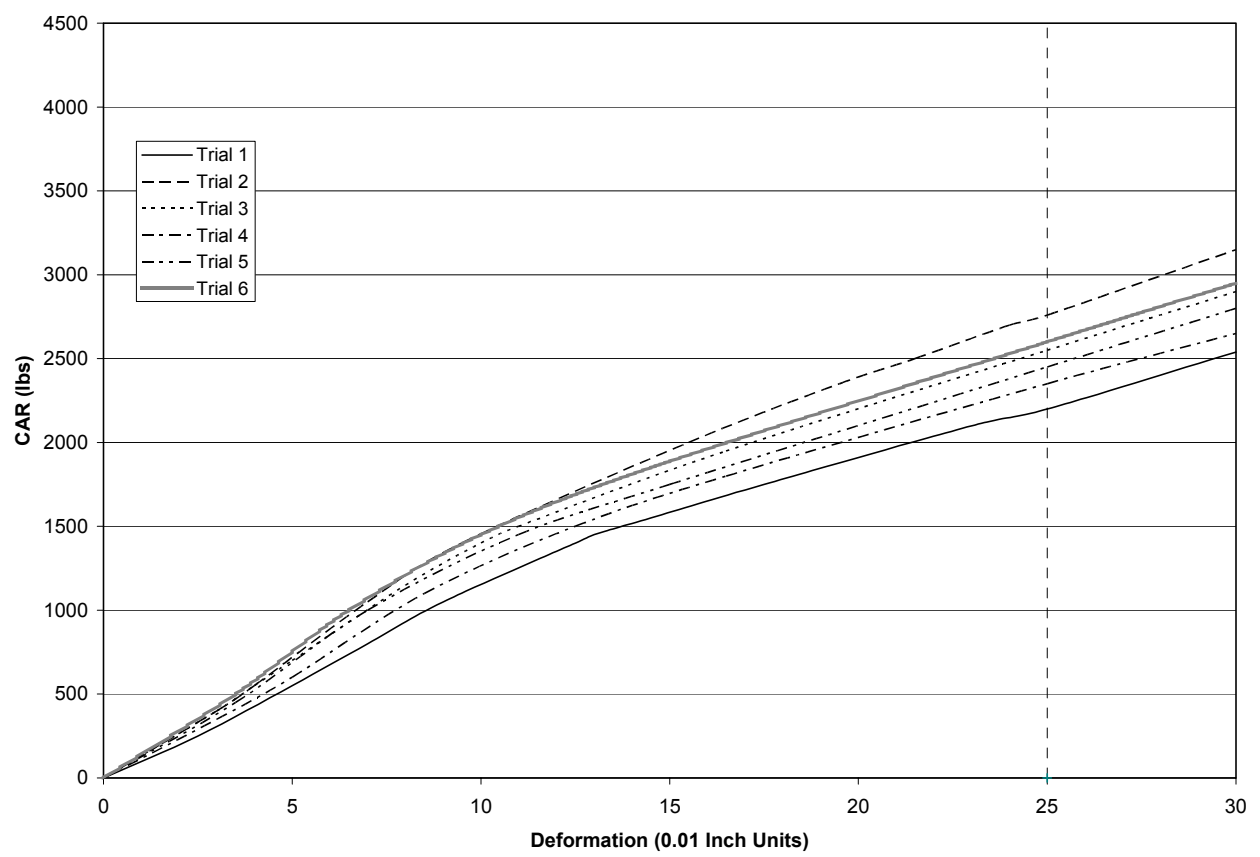

Figure C.1 Blend \#1 CAR results for 100\% limestone

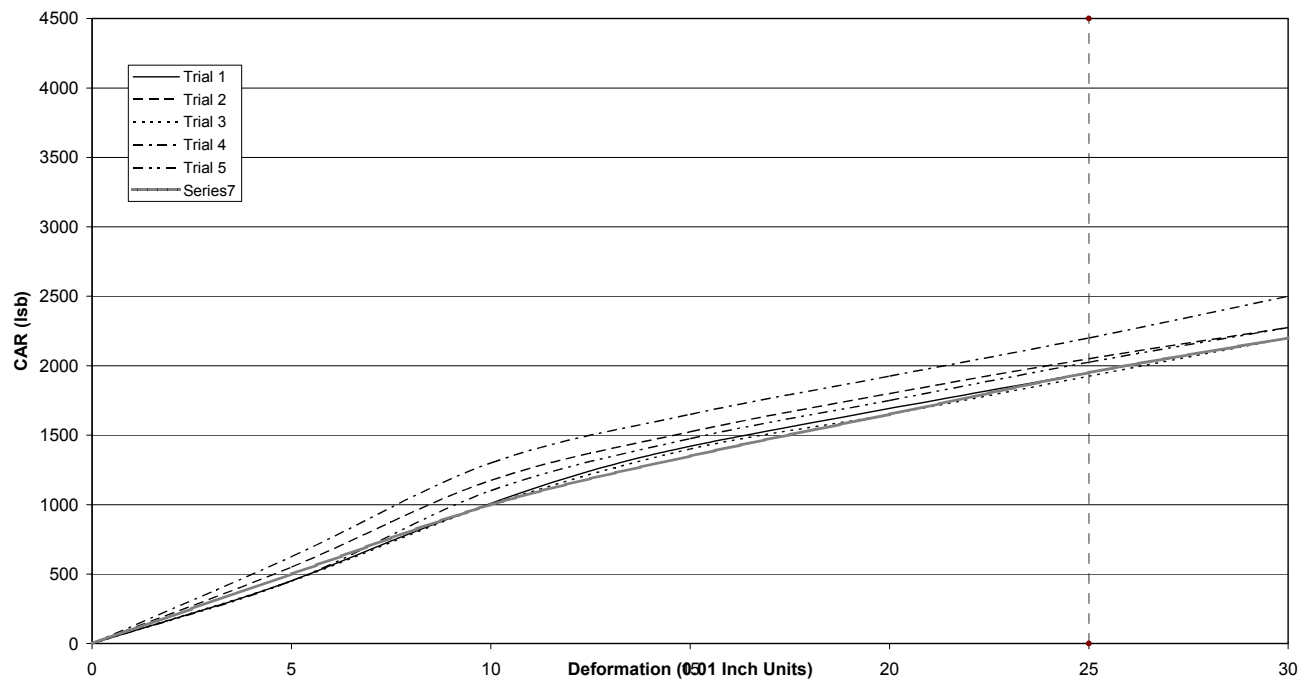

Figure C.2 Blend \#1 CAR results for 75\% limestone/ 25\% natural sand 


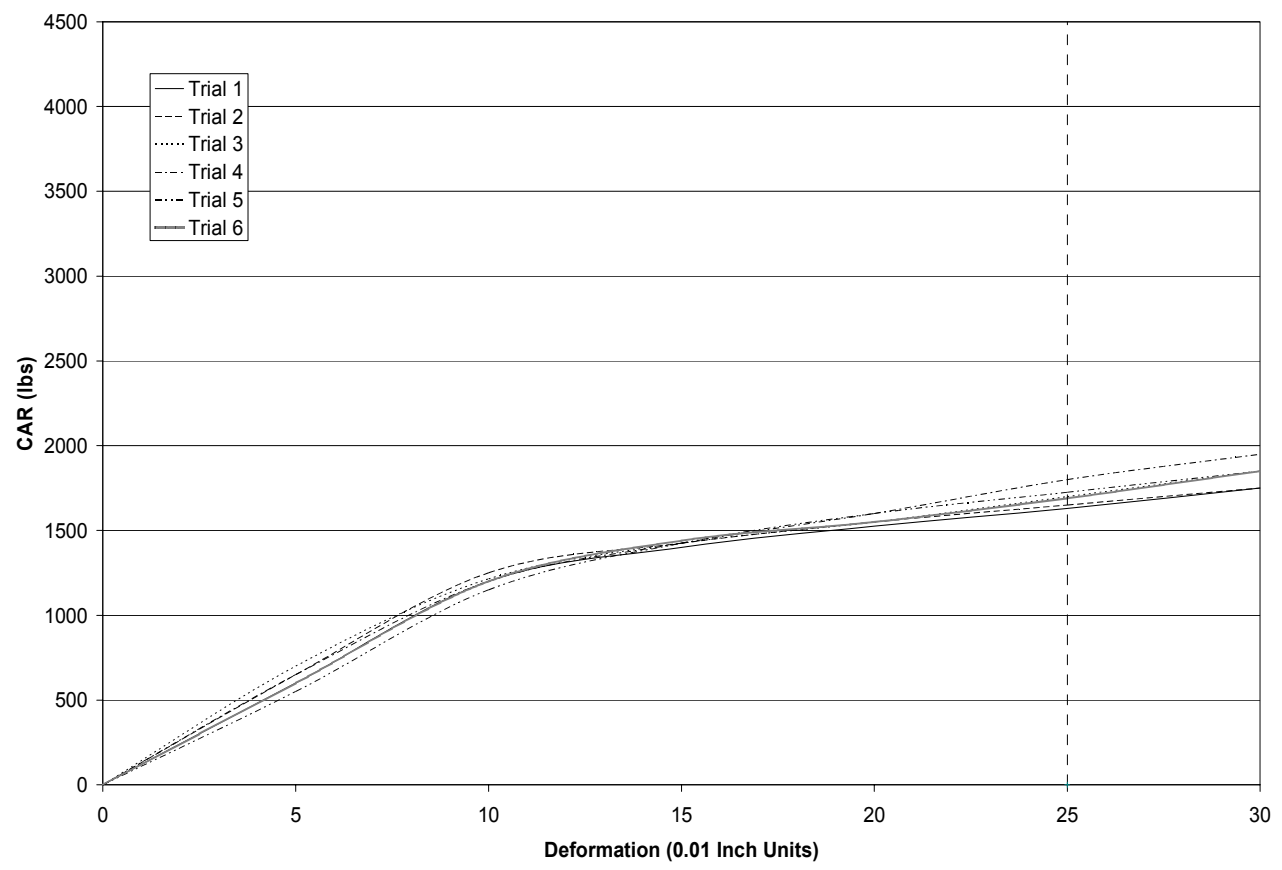

Figure C.3 Blend \#1 CAR results for 50\% limestone/ 50\% natural sand

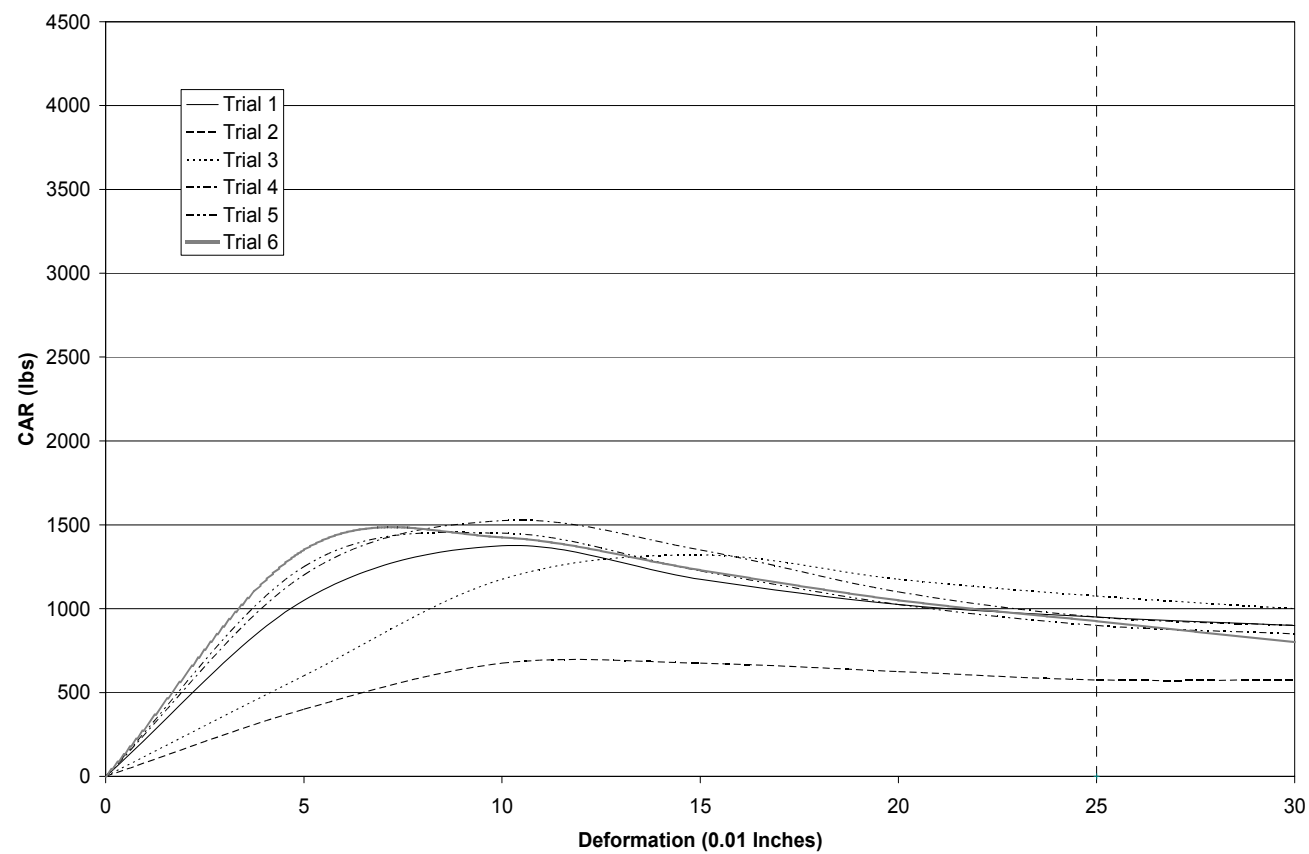

Figure C.4 Blend \#1 CAR results for 25\% limestone/ 75\% natural sand 


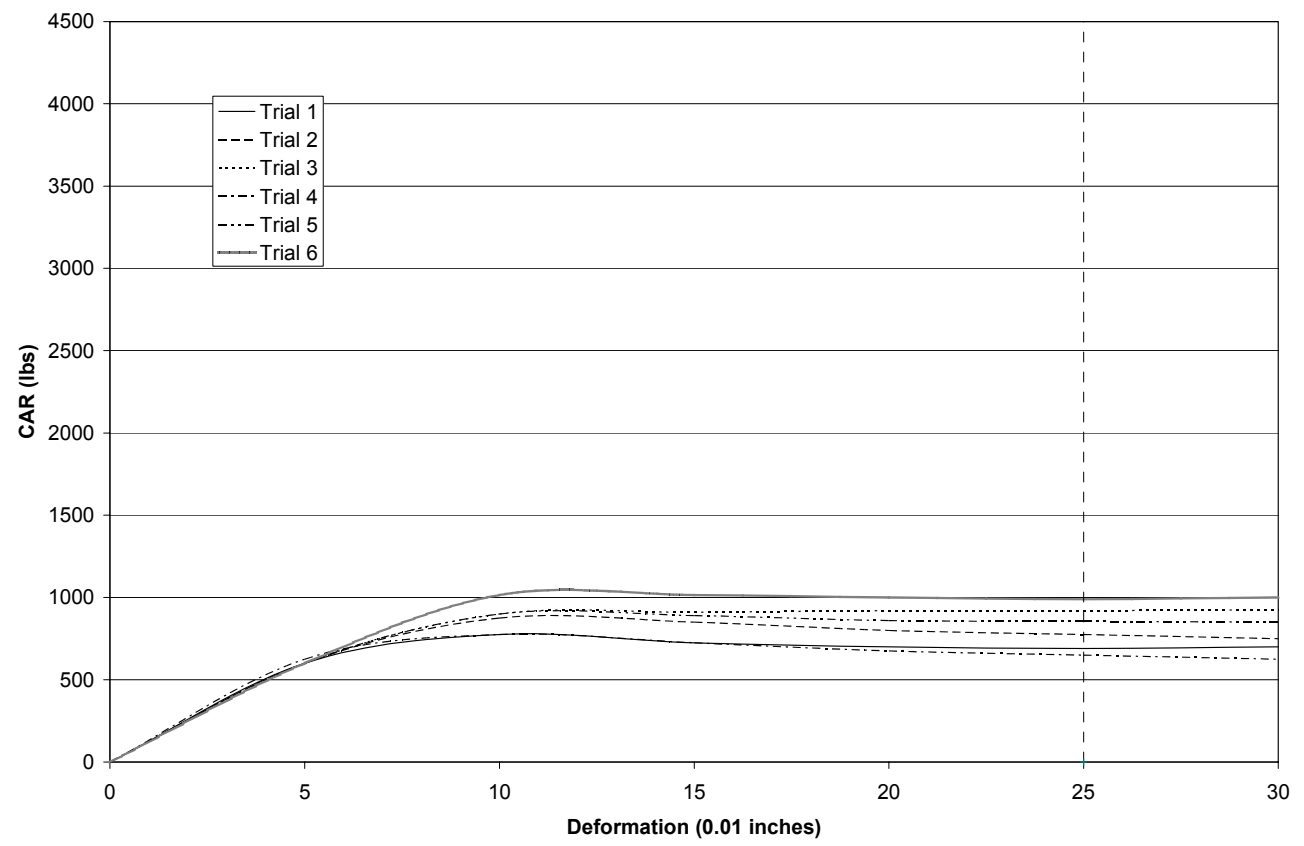

Figure C.5 Blend \#1 CAR results for 100\% natural sand

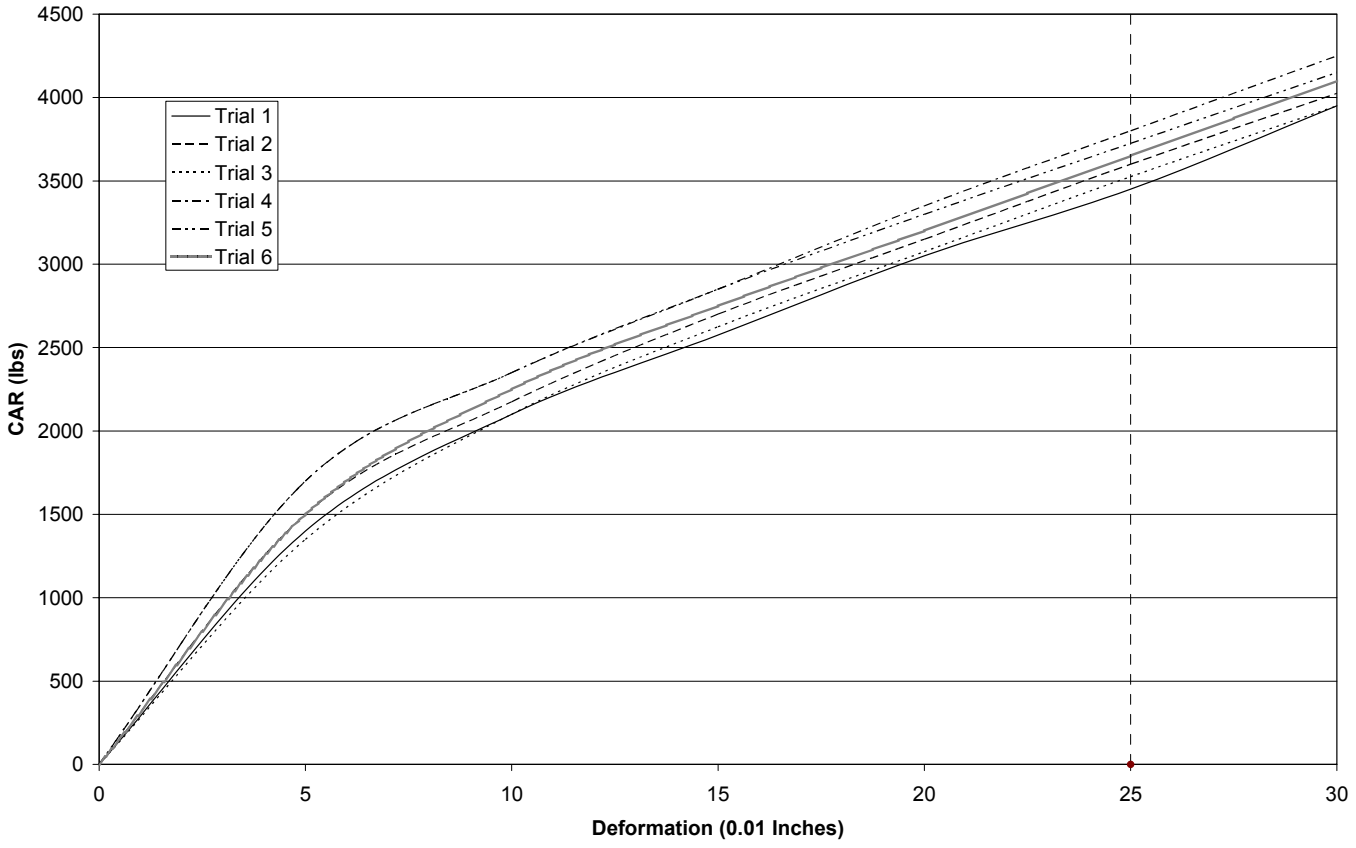

Figure C.6 Blend \#2 CAR results for $100 \%$ limestone 


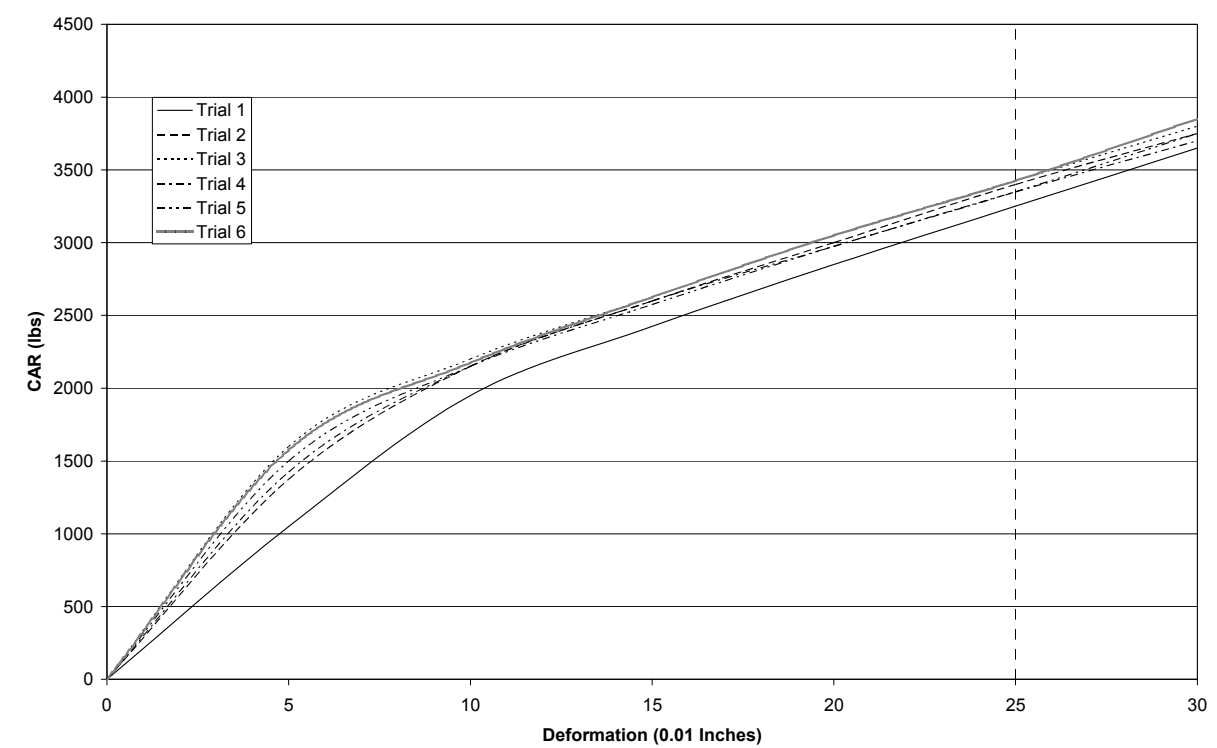

Figure C.7 Blend \#2 CAR results for 75\% limestone/ 25\% natural sand

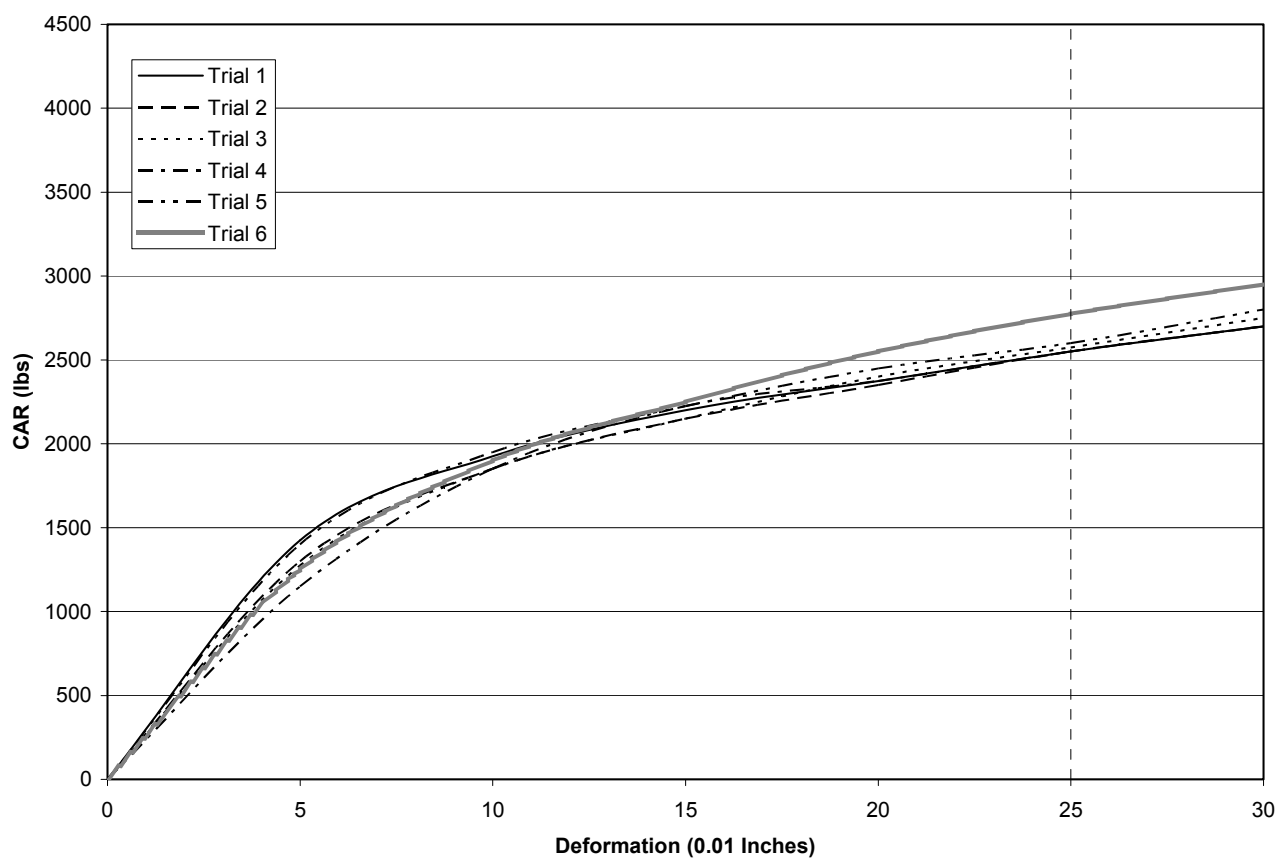

Figure C.8 Blend \#2 CAR results for 50\% limestone/ 50\% natural sand 


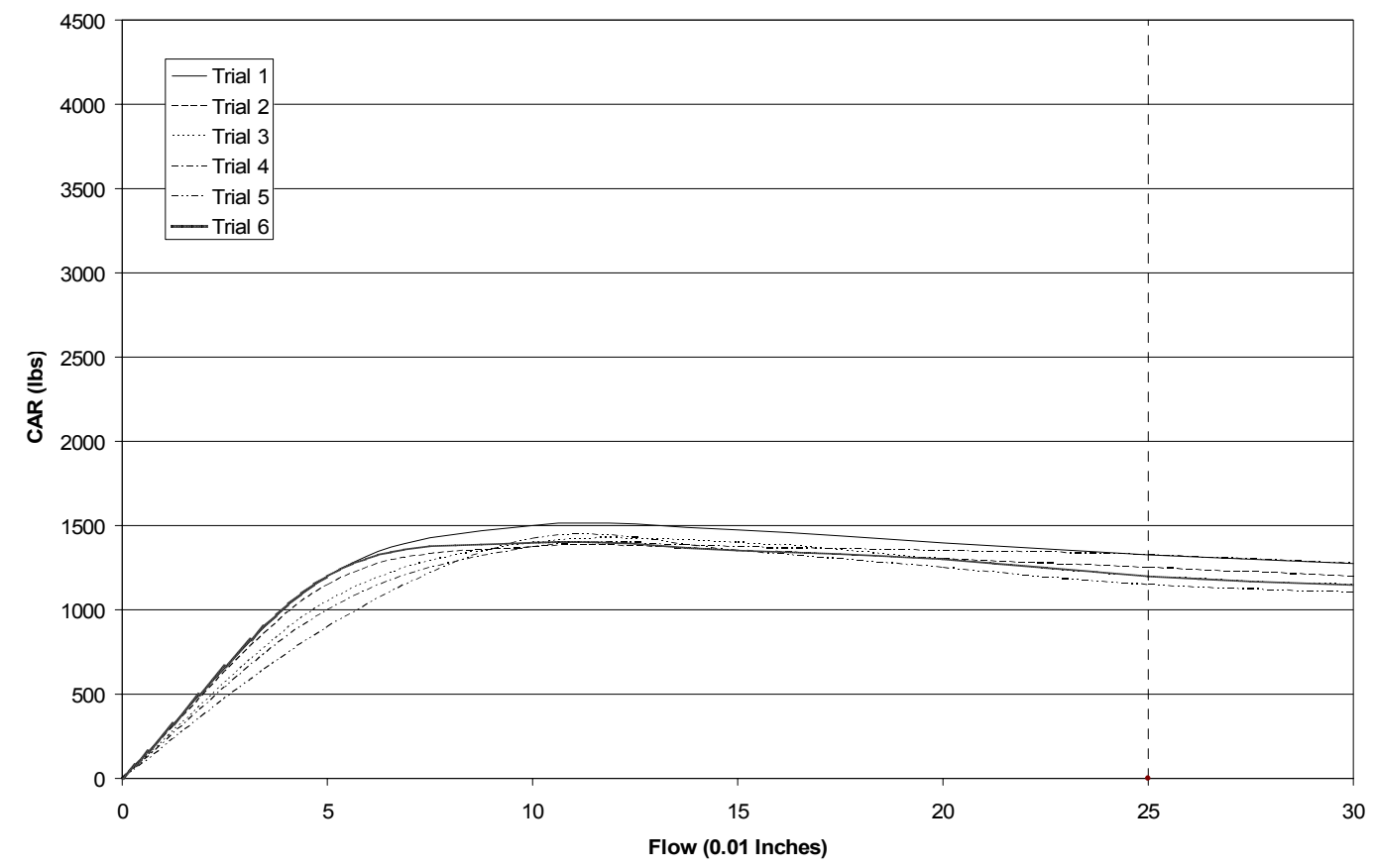

Figure C.9 Blend \#2 CAR results for 25\% limestone/ 75\% natural sand

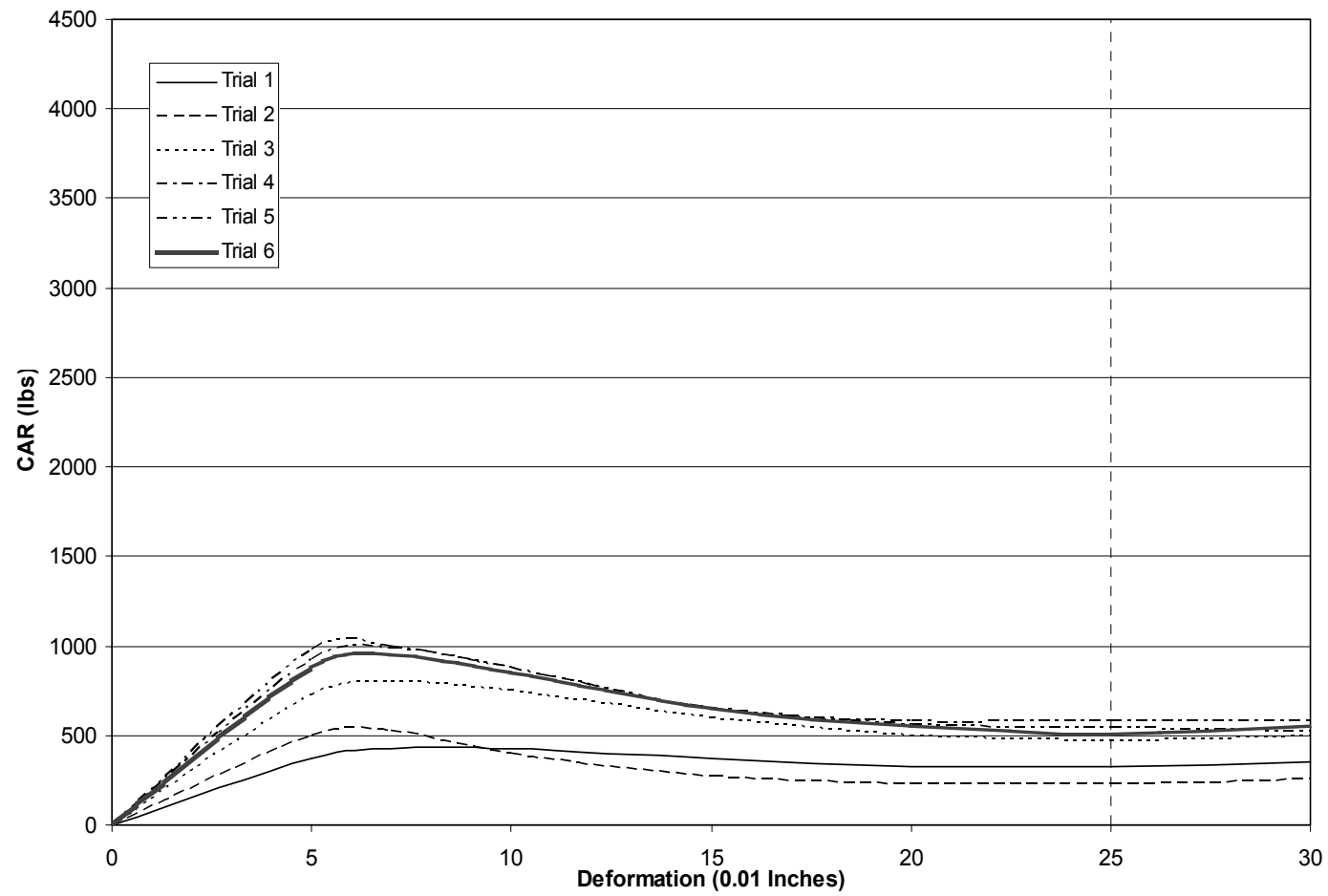

Figure C.10 Blend \#2 CAR results for 100\% natural sand 


\section{APPENDIX D}

\section{RUT DEPTH RESULTS}

Mix Design \#1 (5.2\% AC)

\begin{tabular}{|c|c|c|c|c|c|c|c|c|c|c|c|c|c|}
\hline Limestone Coarse Aggregate & & \multicolumn{12}{|c|}{ APA Rut Depths } \\
\hline $\begin{array}{l}\text { Limestone/River Stone Fine } \\
\text { Aggregate }\end{array}$ & $\mathrm{AC}$ & \multicolumn{2}{|c|}{ Pill 1} & \multicolumn{2}{|c|}{ Pill 2} & \multicolumn{2}{|c|}{ Pill 3} & \multicolumn{2}{|c|}{ Pill 4} & \multicolumn{2}{|c|}{ Pill 5} & \multicolumn{2}{|c|}{ Pill 6} \\
\hline $100 / 0$ & 5.2 & 8 & 8 & 8 & 7.5 & 7 & 6.5 & 5.5 & 4 & 6.5 & 6.5 & 9 & $\begin{array}{l}10 . \\
5\end{array}$ \\
\hline $75 / 25$ & 5.2 & 8 & 8 & 8.5 & 6 & 7.5 & 8 & 7 & 5.5 & 9 & 8.5 & 7 & 6.5 \\
\hline $50 / 50$ & 5.2 & 11.5 & 11.5 & 11 & 9 & 11 & 9 & 8 & 7.5 & 10 & 8 & 9 & 8 \\
\hline $25 / 75$ & 5.2 & 11 & 10 & 9 & 9 & 10 & 10 & 10 & 8 & 10 & 11 & 9 & 10 \\
\hline $0 / 100$ & 5.2 & 15 & 18 & 12 & 15 & 12 & 14 & 15 & 13 & 19 & 19 & 19 & 18 \\
\hline
\end{tabular}

Mix Design \#1 (5.7\% AC)

\begin{tabular}{|c|c|c|c|c|c|c|c|c|c|c|c|c|c|}
\hline Limestone Coarse Aggregate & & \multicolumn{12}{|c|}{ APA Rut Depths } \\
\hline $\begin{array}{l}\text { Limestone/River Stone Fine } \\
\text { Aggregate }\end{array}$ & $\mathrm{AC}$ & \multicolumn{2}{|l|}{ Pill 1} & \multicolumn{2}{|c|}{ Pill 2} & \multicolumn{2}{|c|}{ Pill 3} & \multicolumn{2}{|c|}{ Pill 4} & \multicolumn{2}{|c|}{ Pill 5} & \multicolumn{2}{|c|}{ Pill 6} \\
\hline $100 / 0$ & 5.7 & 9 & 10 & 9.5 & 7.5 & 7.5 & 6 & 5 & 6.5 & 7 & 7 & 7.5 & 7.5 \\
\hline $75 / 25$ & 5.7 & 10.5 & 10 & 11 & 8 & 7 & 8 & 8 & 8 & 12 & 10 & 9.5 & 11 \\
\hline $50 / 50$ & 5.7 & 9.5 & 10.5 & 13 & 9 & 12 & 11.5 & 10 & 10 & 16 & 14 & 13.5 & $\begin{array}{l}13 . \\
5\end{array}$ \\
\hline $25 / 75$ & 5.7 & 13 & 14 & 12.5 & 12 & 12.5 & 13 & 9 & 10 & 13 & 14.5 & 14 & $\begin{array}{l}14 . \\
5\end{array}$ \\
\hline $0 / 100$ & 5.7 & 16 & 17 & 17.5 & 15 & 15 & 14 & 11 & 11 & 21 & 19 & 20 & 20 \\
\hline
\end{tabular}

Mix Design \#1 (6.2\% AC)

\begin{tabular}{|c|c|c|c|c|c|c|c|c|c|c|c|c|c|}
\hline Limestone Coarse Aggregate & & \multicolumn{12}{|c|}{ APA Rut Depths } \\
\hline $\begin{array}{l}\text { Limestone/River Stone Fine } \\
\text { Aggregate }\end{array}$ & $\mathrm{AC}$ & \multicolumn{2}{|c|}{ Pill 1} & \multicolumn{2}{|c|}{ Pill 2} & \multicolumn{2}{|c|}{ Pill 3} & \multicolumn{2}{|c|}{ Pill 4} & \multicolumn{2}{|c|}{ Pill 5} & \multicolumn{2}{|c|}{ Pill 6} \\
\hline $100 / 0$ & 6.2 & 9.5 & 11.5 & 13 & 13 & 11.5 & 12 & 13 & 12.5 & 17.5 & 17.5 & 20 & 24 \\
\hline $75 / 25$ & 6.2 & 18.5 & 19 & 19 & 17 & 13 & 15.5 & 15 & 13.5 & 16 & 16.5 & 18 & 17 \\
\hline $50 / 50$ & 6.2 & 17.5 & 17.5 & 15 & 17 & 15 & 18 & 17 & 15.5 & 19.5 & 21 & 22 & 21 \\
\hline $25 / 75$ & 6.2 & 20 & 21.5 & 24 & 20 & 20.5 & 22 & 19 & 16.5 & 22 & 25 & 26 & 22 \\
\hline $0 / 100$ & 6.2 & 22.5 & 26 & 22.5 & 24 & 21 & 22.5 & 21.5 & 20 & 22 & 24 & 27 & 25 \\
\hline
\end{tabular}

Mix Design \#2 (5.2\% AC)

\begin{tabular}{|c|c|c|c|c|c|c|c|c|c|c|c|c|c|}
\hline $\begin{array}{l}\text { Limestone/Dolomite Coarse } \\
\text { Aggregate }(50 / 50)\end{array}$ & & \multicolumn{12}{|c|}{ APA Rut Depths } \\
\hline $\begin{array}{l}\text { Limestone/River Stone Fine } \\
\text { Aggregate }\end{array}$ & $\mathrm{AC}$ & \multicolumn{2}{|c|}{ Pill 1} & \multicolumn{2}{|c|}{ Pill 2} & \multicolumn{2}{|c|}{ Pill 3} & \multicolumn{2}{|c|}{ Pill 4} & \multicolumn{2}{|c|}{ Pill 5} & \multicolumn{2}{|c|}{ Pill 6} \\
\hline $100 / 0$ & 5.2 & 8 & 9 & 6 & 5.5 & 7 & 4 & 4 & 7 & 5 & 5.5 & 5.5 & 5 \\
\hline $75 / 25$ & 5.2 & 10 & 8 & 8 & 6 & 8 & 6 & 6 & 8 & 8 & 7 & 10 & 6 \\
\hline $50 / 50$ & 5.2 & 11 & 8 & 9.5 & 8 & 8 & 7 & 6.5 & 9 & 8.5 & 8 & 7 & 8 \\
\hline $25 / 75$ & 5.2 & 9 & 11 & 8.5 & 8 & 9 & 8 & 9 & 7.5 & 8 & 10.5 & 7.5 & 8.5 \\
\hline $0 / 100$ & 5.2 & 12 & 11 & 9.5 & 7.5 & 9 & 8 & 8 & 7 & 14 & 14 & 10 & 8 \\
\hline
\end{tabular}




\section{APPENDIX D (CONTINUED) \\ RUT DEPTH RESULTS}

\begin{tabular}{|c|c|c|c|c|c|c|c|c|c|c|c|c|c|}
\hline \multirow{2}{*}{$\begin{array}{l}\text { Limestone/Dolomite Coarse } \\
\text { Aggregate (50/50) } \\
\text { Limestone/River Stone Fine } \\
\text { Aggregate }\end{array}$} & \multirow{3}{*}{$\frac{\mathrm{AC}}{5.7}$} & \multicolumn{12}{|c|}{ APA Rut Depths } \\
\hline & & \multicolumn{2}{|c|}{ Pill 1} & \multicolumn{2}{|c|}{ Pill 2} & \multicolumn{2}{|c|}{ Pill 3} & \multicolumn{2}{|c|}{ Pill 4} & \multicolumn{2}{|c|}{ Pill 5} & \multicolumn{2}{|c|}{ Pill 6} \\
\hline $100 / 0$ & & 6.5 & 6 & 8 & 6 & 7.5 & 7.5 & 7 & 7 & 7.5 & 8 & 7 & 5.5 \\
\hline $75 / 25$ & 5.7 & 9.5 & 8 & 9 & 8 & 10 & 7.5 & 6.5 & 7.5 & 8 & 9 & 6.5 & 6 \\
\hline $50 / 50$ & 5.7 & 9 & 10 & 10 & 9.5 & 10 & 8 & 8 & 10 & 8 & 9 & 12 & 10 \\
\hline $25 / 75$ & 5.7 & 9.5 & 9.5 & 10.5 & 10 & 10.5 & 8.5 & 8.5 & 10.5 & 8.5 & 9.5 & 12.5 & 10.5 \\
\hline $0 / 100$ & 5.7 & 12.5 & 12.5 & 10 & 10 & 10.5 & 10 & 11 & 10.5 & 12 & 14 & 15 & 12 \\
\hline
\end{tabular}

Mix Design \#2 (6.2\% AC)

\begin{tabular}{|c|c|c|c|c|c|c|c|c|c|c|c|c|c|}
\hline $\begin{array}{l}\text { Limestone/Dolomite Coarse } \\
\text { Aggregate }(50 / 50)\end{array}$ & & \multicolumn{12}{|c|}{ APA Rut Depths } \\
\hline $\begin{array}{l}\text { Limestone/River Stone Fine } \\
\text { Aggregate }\end{array}$ & $\mathrm{AC}$ & \multicolumn{2}{|c|}{ Pill 1} & \multicolumn{2}{|c|}{ Pill 2} & \multicolumn{2}{|c|}{ Pill 3} & \multicolumn{2}{|c|}{ Pill 4} & \multicolumn{2}{|c|}{ Pill 5} & \multicolumn{2}{|c|}{ Pill 6} \\
\hline $100 / 0$ & 6.2 & 10 & 7 & 9 & 7 & 7 & 7.5 & 8 & 8.5 & 8 & 9 & 9 & 6 \\
\hline $75 / 25$ & 6.2 & 8 & 8 & 12.5 & 12.5 & 10 & 10 & 9.5 & 7.5 & 11 & 12 & 11.5 & 11 \\
\hline $50 / 50$ & 6.2 & 13 & 12 & 13 & 12.5 & 13 & 13 & 9 & 11 & 14 & 14.5 & 12 & 10 \\
\hline $25 / 75$ & 6.2 & 10 & 9 & 16 & 14.5 & 17.5 & 16 & 15.5 & 14 & 22 & 22 & 17 & 19.5 \\
\hline $0 / 100$ & 6.2 & 19.5 & 18 & 18 & 16.5 & 16.5 & 19 & 19 & 16.5 & 19 & 18.5 & 17 & 13 \\
\hline
\end{tabular}


APPENDIX E

VOLUMETRIC ANALYSIS

\begin{tabular}{|c|c|c|c|c|c|c|c|c|c|c|c|c|c|c|c|c|c|c|}
\hline \multirow{2}{*}{$\begin{array}{c}\text { Asphalt } \\
\text { Content } \\
\%\end{array}$} & \multirow[b]{2}{*}{ Blend } & \multirow[b]{2}{*}{$\begin{array}{l}\text { Fine agg \% } \\
\text { Limestone }\end{array}$} & \multirow[b]{2}{*}{ Gsb } & \multirow[b]{2}{*}{ Pill } & \multicolumn{4}{|l|}{ Rice } & \multicolumn{10}{|l|}{ Bulk } \\
\hline & & & & & $\begin{array}{l}\text { Dry } \\
\text { Wgt }\end{array}$ & $\begin{array}{l}\text { Sub } \\
\text { Wgt }\end{array}$ & Bowl & Gmm & $\begin{array}{l}\text { Dry } \\
\text { Wgt. }\end{array}$ & $\begin{array}{l}\text { Sub } \\
\text { Wgt }\end{array}$ & $\begin{array}{l}\text { SSD } \\
\text { Wgt }\end{array}$ & $\mathrm{Gmb}$ & VTM & VMA & VFA & $\begin{array}{l}\text { Avg } \\
\text { VTM }\end{array}$ & $\begin{array}{l}\text { Avg } \\
\text { VMA }\end{array}$ & $\begin{array}{l}\text { Avg } \\
\text { VFA }\end{array}$ \\
\hline \multirow{20}{*}{5.2} & \multirow{10}{*}{1} & 100 & 2.623 & 1 & 2381.6 & 2625.0 & 1330.0 & 2.500 & 4706.5 & 2750.8 & 4716.2 & 2.395 & 4.2 & 13.4 & 68.7 & 3.80 & 13.10 & 71.05 \\
\hline & & & & 2 & & & & & 4750.0 & 2789.8 & 4757.5 & 2.414 & 3.4 & 12.8 & 73.4 & & & \\
\hline & & 75 & 2.590 & 1 & 2138.0 & 2790.8 & 1508.9 & 2.497 & 4721.6 & 2761.4 & 4732.7 & 2.395 & 4.1 & 12.3 & 66.7 & 3.65 & 11.90 & 69.45 \\
\hline & & & & 2 & & & & & 4769.4 & 2803.6 & 4776.6 & 2.417 & 3.2 & 11.5 & 72.2 & & & \\
\hline & & 50 & 2.557 & 1 & 2172.4 & 2630.7 & 1330.0 & 2.492 & 4775.5 & 2792.9 & 4783.6 & 2.399 & 3.7 & 11.1 & 66.7 & 3.95 & 11.30 & 65.10 \\
\hline & & & & 2 & & & & & 4759.0 & 2774.3 & 4768.4 & 2.387 & 4.2 & 11.5 & 63.5 & & & \\
\hline & & 25 & 2.524 & 1 & 2181.4 & 2812.2 & 1508.9 & 2.484 & 4777.2 & 2789.1 & 4783.9 & 2.395 & 3.6 & 10 & 64 & 3.85 & 10.30 & 62.65 \\
\hline & & & & 2 & & & & & 4740.5 & 2757.2 & 4748.2 & 2.381 & 4.1 & 10.6 & 61.3 & & & \\
\hline & & 0 & 2.491 & 1 & 2154.8 & 2599.7 & 1330.0 & 2.435 & 4772.6 & 2779.7 & 4779.6 & 2.386 & 2 & 9.2 & 78.3 & 2.10 & 9.25 & 77.30 \\
\hline & & & & 2 & & & & & 4757.9 & 2767.4 & 4765.0 & 2.382 & 2.2 & 9.3 & 76.3 & & & \\
\hline & \multirow{10}{*}{2} & 100 & 2.619 & 1 & 2197.4 & 2651.5 & 1330.0 & 2.509 & 4795.6 & 2769.7 & 4818.3 & 2.341 & 6.7 & 15.2 & 55.9 & 6.90 & 15.40 & 55.20 \\
\hline & & & & 2 & & & & & 4769.1 & 2746.3 & 4791.3 & 2.332 & 7.1 & 15.6 & 54.5 & & & \\
\hline & & 75 & 2.589 & 1 & 2185.3 & 2820.7 & 1508.9 & 2.502 & 4770.2 & 2748.3 & 4792.0 & 2.334 & 6.7 & 14.6 & 54.1 & 6.75 & 14.65 & 53.90 \\
\hline & & & & 2 & & & & & 4779.0 & 2751.4 & 4802.0 & 2.331 & 6.8 & 14.7 & 53.7 & & & \\
\hline & & 50 & 2.560 & 1 & 2186.4 & 2642.2 & 1330.0 & 2.501 & 4784.7 & 2753.2 & 4805.3 & 2.332 & 6.8 & 13.7 & 50.4 & 8.10 & 14.90 & 46.00 \\
\hline & & & & 2 & & & & & 4704.4 & 2669.1 & 4744.4 & 2.267 & 9.4 & 16.1 & 41.6 & & & \\
\hline & & 25 & 2.531 & 1 & 1193.4 & 2223.7 & 1508.9 & 2.494 & 4750.0 & 2701.2 & 4775.8 & 2.290 & 8.2 & 14.2 & 42.3 & 8.05 & 14.05 & 42.75 \\
\hline & & & & 2 & & & & & 4769.2 & 2718.8 & 4793.8 & 2.298 & 7.9 & 13.9 & 43.2 & & & \\
\hline & & 0 & 2.502 & 1 & 2172.9 & 2630.8 & 1330.0 & 2.492 & 4771.4 & 2715.2 & 4797.4 & 2.292 & 8 & 13.2 & 39.4 & 8.20 & 13.35 & 38.60 \\
\hline & & & & 2 & & & & & 4760.3 & 2711.7 & 4797.1 & 2.283 & 8.4 & 13.5 & 37.8 & & & \\
\hline
\end{tabular}


APPENDIX E (CONTINUED)

VOLUMETRIC ANALYSIS

\begin{tabular}{|c|c|c|c|c|c|c|c|c|c|c|c|c|c|c|c|c|c|c|}
\hline \multirow{2}{*}{$\begin{array}{c}\text { Asphalt } \\
\text { Content } \\
\%\end{array}$} & \multirow[b]{2}{*}{ Blend } & \multirow{2}{*}{$\begin{array}{c}\text { Fine agg } \\
\% \\
\text { Limestone }\end{array}$} & \multirow[b]{2}{*}{ Gsb } & \multirow[b]{2}{*}{ Pill } & \multicolumn{4}{|l|}{ Rice } & \multicolumn{10}{|l|}{ Bulk } \\
\hline & & & & & $\begin{array}{l}\text { Dry } \\
\text { Wgt }\end{array}$ & $\begin{array}{l}\text { Sub } \\
\text { Wgt }\end{array}$ & Bowl & $\mathrm{Gmm}$ & $\begin{array}{l}\text { Dry } \\
\text { Wgt. }\end{array}$ & $\begin{array}{l}\text { Sub } \\
\text { Wgt }\end{array}$ & $\begin{array}{l}\text { SSD } \\
\text { Wgt }\end{array}$ & $\mathrm{Gmb}$ & VTM & VMA & VFA & $\begin{array}{c}\text { Avg } \\
\text { VTM }\end{array}$ & $\begin{array}{c}\text { Avg } \\
\text { VMA }\end{array}$ & $\begin{array}{l}\text { Avg } \\
\text { VFA }\end{array}$ \\
\hline \multirow{20}{*}{5.7} & \multirow{10}{*}{1} & 100 & 2.623 & 1 & 2160.2 & 2620.0 & 1330.0 & 2.482 & 4703.9 & 2757.5 & 4715.8 & 2.402 & 3.2 & 13.2 & 75.8 & 2.95 & 12.95 & 77.25 \\
\hline & & & & 2 & & & & & 4700.7 & 2765.8 & 4711.1 & 2.416 & 2.7 & 12.7 & 78.7 & & & \\
\hline & & 75 & 2.590 & 1 & 2147.2 & 2787.4 & 1508.9 & 2.472 & 4715.5 & 2781.4 & 4721.6 & 2.430 & 1.7 & 11.1 & 84.7 & 2.05 & 11.40 & 82.10 \\
\hline & & & & 2 & & & & & 4671.9 & 2744.5 & 4681.3 & 2.412 & 2.4 & 11.7 & 79.5 & & & \\
\hline & & 50 & 2.557 & 1 & 2088.6 & 2574.2 & 1330.0 & 2.473 & 4691.7 & 2750.8 & 4700.5 & 2.406 & 2.7 & 10.8 & 75 & 2.40 & 10.50 & 77.20 \\
\hline & & & & 2 & & & & & 4722.5 & 2778.6 & 4729.6 & 2.421 & 2.1 & 10.2 & 79.4 & & & \\
\hline & & 25 & 2.524 & 1 & 2155.6 & 2793.0 & 1508.9 & 2.473 & 4736.0 & 2754.2 & 4744.1 & 2.380 & 3.8 & 10.6 & 64.2 & 3.75 & 10.60 & 64.65 \\
\hline & & & & 2 & & & & & 4745.4 & 2757.8 & 4751.1 & 2.381 & 3.7 & 10.6 & 65.1 & & & \\
\hline & & 0 & 2.491 & 1 & 2195.4 & 2633.9 & 1330.0 & 2.463 & 4714.3 & 2738.5 & 4720.3 & 2.379 & 3.4 & 9.5 & 64.2 & 3.45 & 9.50 & 63.70 \\
\hline & & & & 2 & & & & & 4743.1 & 2754.1 & 4749.4 & 2.377 & 3.5 & 9.5 & 63.2 & & & \\
\hline & \multirow{10}{*}{2} & 100 & 2.619 & 1 & 1191.9 & 2042.1 & 1330.0 & 2.484 & 4770.2 & 2739.2 & 4792.8 & 2.323 & 6.5 & 15.9 & 59.1 & 5.90 & 15.40 & 61.75 \\
\hline & & & & 2 & & & & & 4775.4 & 2757.7 & 4787.8 & 2.352 & 5.3 & 14.9 & 64.4 & & & \\
\hline & & 75 & 2.589 & 1 & 1188.4 & 2217.9 & 1508.9 & 2.479 & 4766.6 & 2741.5 & 4783.1 & 2.335 & 5.8 & 14.5 & 60 & 5.95 & 14.60 & 59.25 \\
\hline & & & & 2 & & & & & 4741.5 & 2724.8 & 4760.6 & 2.329 & 6.1 & 14.7 & 58.5 & & & \\
\hline & & 50 & 2.560 & 1 & 1177.1 & 2033.3 & 1330.0 & 2.484 & 4760.2 & 2735.5 & 4775.6 & 2.333 & 6.1 & 13.6 & 55.1 & 6.50 & 14.00 & 53.60 \\
\hline & & & & 2 & & & & & 4763.3 & 2727.1 & 4787.5 & 2.312 & 6.9 & 14.4 & 52.1 & & & \\
\hline & & 25 & 2.531 & 1 & 1184.5 & 2215.7 & 1508.9 & 2.480 & 4757.6 & 2710.4 & 4778.8 & 2.300 & 7.3 & 13.9 & 47.5 & 7.50 & 14.10 & 46.85 \\
\hline & & & & 2 & & & & & 4719.4 & 2679.6 & 4741.5 & 2.289 & 7.7 & 14.3 & 46.2 & & & \\
\hline & & 0 & 2.502 & 1 & 1183.5 & 2036.0 & 1330.0 & 2.479 & 4768.8 & 2718.6 & 4784.7 & 2.308 & 6.9 & 12.6 & 45.2 & 7.05 & 12.70 & 44.50 \\
\hline & & & & 2 & & & & & 4775.4 & 2719.9 & 4795.2 & 2.301 & 7.2 & 12.8 & 43.8 & & & \\
\hline
\end{tabular}




\section{APPENDIX E (CONTINUED)}

VOLUMETRIC ANALYSIS

\begin{tabular}{|c|c|c|c|c|c|c|c|c|c|c|c|c|c|c|c|c|c|c|}
\hline \multirow{2}{*}{$\begin{array}{c}\text { Asphalt } \\
\text { Content } \\
\% \\
\end{array}$} & \multirow[b]{2}{*}{ Blend } & \multirow[b]{2}{*}{$\begin{array}{l}\text { Fine agg \% } \\
\text { Limestone }\end{array}$} & \multirow[b]{2}{*}{ Gsb } & \multirow[b]{2}{*}{ Pill } & \multicolumn{4}{|l|}{ Rice } & \multicolumn{10}{|l|}{ Bulk } \\
\hline & & & & & $\begin{array}{l}\text { Dry } \\
\text { Wgt }\end{array}$ & $\begin{array}{l}\text { Sub } \\
\text { Wgt }\end{array}$ & Bowl & $\mathrm{Gmm}$ & $\begin{array}{l}\text { Dry } \\
\text { Wgt. }\end{array}$ & $\begin{array}{l}\text { Sub } \\
\text { Wgt }\end{array}$ & $\begin{array}{l}\text { SSD } \\
\text { Wgt }\end{array}$ & $\mathrm{Gmb}$ & VTM & VMA & VFA & $\begin{array}{l}\text { Avg } \\
\text { VTM }\end{array}$ & $\begin{array}{l}\text { Avg } \\
\text { VMA }\end{array}$ & $\begin{array}{l}\text { Avg } \\
\text { VFA }\end{array}$ \\
\hline \multirow{20}{*}{6.7} & \multirow{10}{*}{1} & 100 & 2.623 & 1 & 2151.0 & 2777.8 & 1508.9 & 2.438 & 4635.8 & 2720.8 & 4640.7 & 2.415 & 0.9 & 12.7 & 92.9 & 0.80 & 12.60 & 93.65 \\
\hline & & & & 2 & & & & & 4684.4 & 2752.9 & 4688.9 & 2.420 & 0.7 & 12.5 & 94.4 & & & \\
\hline & & 75 & 2.590 & 1 & 2153.1 & 2600.1 & 1330.0 & 2.438 & 4656.5 & 2730.2 & 4662.4 & 2.410 & 1.1 & 11.8 & 90.7 & 1.10 & 11.80 & 90.70 \\
\hline & & & & 2 & & & & & 4672.1 & 2738.2 & 4677.2 & 2.410 & 1.1 & 11.8 & 90.7 & & & \\
\hline & & 50 & 2.557 & 1 & 2165.6 & 2787.1 & 1508.9 & 2.440 & 4680.7 & 2704.8 & 4686.0 & 2.363 & 3.2 & 12.4 & 74.2 & 2.00 & 11.30 & 83.20 \\
\hline & & & & 2 & & & & & 4646.8 & 2732.7 & 4652.0 & 2.421 & 0.8 & 10.2 & 92.2 & & & \\
\hline & & 25 & 2.524 & 1 & 2182.2 & 2615.5 & 1330.0 & 2.434 & 4708.5 & 2758.5 & 4713.4 & 2.409 & 1 & 9.5 & 89.5 & 1.15 & 9.60 & 88.05 \\
\hline & & & & 2 & & & & & 4673.7 & 2735.0 & 4679.7 & 2.403 & 1.3 & 9.7 & 86.6 & & & \\
\hline & & 0 & 2.491 & 1 & 2171.6 & 2787.1 & 1508.9 & 2.431 & 4691.8 & 2748.1 & 4696.6 & 2.408 & 0.9 & 8.3 & 89.2 & 0.95 & 8.35 & 88.65 \\
\hline & & & & 2 & & & & & 4673.0 & 2736.6 & 4678.1 & 2.407 & 1 & 8.4 & 88.1 & & & \\
\hline & \multirow{10}{*}{2} & 100 & 2.619 & 1 & 1179.2 & 2206.0 & 1508.9 & 2.446 & 4754.3 & 2743.0 & 4767.9 & 2.348 & 4 & 15 & 73.3 & 3.90 & 14.90 & 73.80 \\
\hline & & & & 2 & & & & & 4757.4 & 2748.1 & 4770.1 & 2.353 & 3.8 & 14.8 & 74.3 & & & \\
\hline & & 75 & 2.589 & 1 & 1197.4 & 2036.5 & 1330.0 & 2.439 & 4755.3 & 2743.1 & 4767.0 & 2.350 & 3.6 & 14 & 74.3 & 3.70 & 14.05 & 73.65 \\
\hline & & & & 2 & & & & & 4752.1 & 2740.0 & 4765.2 & 2.346 & 3.8 & 14.1 & 73 & & & \\
\hline & & 50 & 2.560 & 1 & 1184.8 & 2208.2 & 1508.9 & 2.440 & 4758.7 & 2747.5 & 4766.1 & 2.357 & 3.4 & 12.7 & 73.2 & 3.40 & 12.70 & 73.20 \\
\hline & & & & 2 & & & & & 4747.7 & 2738.2 & 4752.2 & 2.357 & 3.4 & 12.7 & 73.2 & & & \\
\hline & & 25 & 2.531 & 1 & 1189.0 & 2030.9 & 1330.0 & 2.436 & 4753.5 & 2735.1 & 4763.5 & 2.343 & 3.8 & 12.2 & 68.9 & 3.70 & 12.10 & 69.45 \\
\hline & & & & 2 & & & & & 4764.5 & 2746.2 & 4774.4 & 2.349 & 3.6 & 12 & 70 & & & \\
\hline & & 0 & 2.502 & 1 & 1184.8 & 2207.3 & 1508.9 & 2.436 & 4747.0 & 2724.6 & 4757.2 & 2.335 & 4.1 & 11.5 & 64.3 & 3.95 & 11.35 & 65.20 \\
\hline & & & & 2 & & & & & 4766.0 & 2743.2 & 4777.2 & 2.343 & 3.8 & 11.2 & 66.1 & & & \\
\hline
\end{tabular}




\section{VITA}

Sean P. Rafferty was born in Latrobe, Pennsylvania on March 21, 1979. He received his Bachelor of Science degree in Civil and Environmental Engineering from West Virginia University in December 2001. He has completed a cooperative workstudy program for the United States Army Core of Engineers Water Management Division, Pittsburgh District. Sean has also completed an internship as a safety engineer with Mail-Well Envelope, Los Angeles.

Sean has since completed graduate level course work in the areas of pavement design, highway engineering, construction management and concrete design, and has successfully passed the Fundamentals of Engineering exam. He is currently a candidate for the Master of Science degree in Civil Engineering at West Virginia University, and plans to graduate in May 2003. 